\title{
Measuring unfair (in)equality
}

\author{
Ingvild Almås Alexander W. Cappelen Jo Thori Lind \\ Erik Ø. Sørensen Bertil Tungodden*
}

\begin{abstract}
The standard approach to inequality measurement regards all inequalities as unfair. However, most people do not share this view, and believe that some inequalities are fair. This paper shows one way of generalizing the standard approach to take account of the distinction between fair and unfair inequalities. Within this framework, we introduce the unfairness Lorenz curve and the unfairness Gini, which are generalizations of the standard versions of the Lorenz curve and the Gini.

With this more general framework in place, we study the implications of responsibility-sensitive theories of justice for the evaluation of the income distribution in Norway from 1986 to 2005 . We find that the pre-tax income distribution has become unfairer in Norway, even though the standard Gini has decreased over the same period, and we show that an important explanation of this finding is the change in women's economic situation. Finally, we show that the post-tax income distribution also has become unfairer, partly due to the tax system in Norway contributing less to the elimination of unfairness in 1986 than in 2005.(JEL: D31, D63, J31. Keywords: Income inequality, Fairness.)
\end{abstract}

\section{Introduction}

Most people view a strict egalitarian income distribution as unfair. It is evident from the political debate, surveys (Gaertner and Schwettmann, 2007; Schokkaert and Devooght, 2003), economic experiments (Cappelen, Hole, Sørensen, and Tungodden,

*Almås: Norwegian School of Economics and Business Administration, Bergen, and University of Oslo, email: ingvild.almas@nhh.no (corresponding author); Cappelen: Norwegian School of Economics and Business Administration, Bergen, email: alexander.cappelen@nhh.no; Thori Lind: University of Oslo, email: j.t.lind@econ.uio.no; Sørensen: Norwegian School of Economics and Business Administration, Bergen, email: sameos@gmail.com; Tungodden: Norwegian School of Economics and Business Administration, Bergen, and Chr. Michelsen Institute, Bergen, email: bertil.tungodden@nhh.no. We should like to thank the editor, two anonymous referees, Marc Fleurbaey and John Roemer for valuable comments and suggestions. 
2007; Frohlich, Oppenheimer, and Kurki, 2004; Konow, 2000) and contemporary theories of justice (Arneson, 1989; Bossert, 1995; Fleurbaey, 1995; Roemer, 1996, 1998) that people view some inequalities, e.g. inequalities arising from differences in the number of hours worked, as fair, and other inequalities, e.g. inequalities arising from gender or race, as unfair. Hence, we can have both unfair equalities and unfair inequalities, and the question is how we should measure overall unfair (in)equality, or unfairness, in society.

The standard approach to inequality measurement does not make a distinction between fair and unfair inequalities. All inequalities are considered unfair, and any movement towards a more equal distribution is considered an improvement in terms of fairness. However, such a movement may take place through eliminating what many consider to be fair inequalities, and thus, may actually represent a step towards a more unfair society. Therefore, we propose a framework for inequality measurement that allows for alternative viewpoints of what is a fair income distribution. The defining feature of our approach is that, for a given interpretation of a fair income distribution, we measure how much each individual's actual income deviates from what would be his fair income.

Alternative approaches to cope with the distinction between fair and unfair inequalities are given in Bourguignon, Ferreira, and Menéndez (2007); Devooght (2008); Roemer, Aaberge, Colombino, Fritzell, Jenkins, Marx, Page, Pommer, RuizCastillo, San Segundo, Tranaes, Wagner, and Zurbiri (2003). Our paper differs from these by generalizing the standard framework of inequality measurement and by introducing the unfairness Lorenz curve and the unfairness Gini as generalizations of their standard counterparts. This makes it straightforward to compare our measure of unfairness and the standard Gini. In fact, the standard approach is a special case within this framework, in which the fair income of each individual is equal to the mean income in society.

With this more general framework in place, we study the implications of responsibility-sensitive theories of justice for the evaluation of the pre-tax income distribution in Norway from 1986 to 2005, where a responsibility-sensitive theory 
of justice specifies what are acceptable and unacceptable sources of inequality in society. In particular, we focus on the implications of applying a generalized version of the proportionality principle (Bossert, 1995; Cappelen and Tungodden, 2007; Konow, 1996). Our main finding is that the pre-tax income distribution in Norway has become less fair, even though the standard Gini has decreased in the same period. We show that this holds for different views on what individuals should be held responsible for, and for alternative specifications of responsibility-sensitive theories of justice. We also show that an important explanation of this finding is the change in women's economic situation, reflected in an increase in the share of women in the labor force and an increase in the average number of hours worked by women. Finally, we show that there also has been an increase in unfairness in the post-tax income distribution in the period. This is partly due to the increase in unfairness in the pre-tax income distribution, but also partly due to the tax system in Norway contributing less to the elimination of unfairness in 1986 than in 2005.

Section 2 generalizes the standard approach to inequality measurement. Section 3 introduces the generalized proportionality principle and the responsibility cut. Section 4 describes the data for Norway and the estimation of the labor earnings equation. The main empirical analysis is presented in Section 5, whereas Section 6 presents several robustness tests. Section 7 extends the analysis also to cover the post-tax income distribution. Section 8 provides some concluding comments.

\section{Generalizing the standard framework}

In this section, we show how the standard framework of inequality measurement, which measures deviation from a norm income distribution of strict equality, can be generalized to cover other ideas of a fair income distribution. Formally, in this section we assume that any alternative, $\boldsymbol{A}$, contains a set of individuals, $\boldsymbol{N}=\{1, \ldots, n\}$. Each individual, $i$, is characterized by the pair, $\left(y_{i}^{\boldsymbol{A}}, z_{i}^{\boldsymbol{A}}\right)$, where $y_{i}^{\boldsymbol{A}} \geq 0$ is the actual income and $z_{i}^{\boldsymbol{A}} \geq 0$ is the fair income of individual $i$ in $\boldsymbol{A}$. Hence, an alternative $\boldsymbol{A}$ is characterized by $\boldsymbol{A}=\left[\left(y_{1}^{\boldsymbol{A}}, z_{1}^{\boldsymbol{A}}\right), \ldots,\left(y_{n}^{\boldsymbol{A}}, z_{n}^{\boldsymbol{A}}\right)\right]$, where the average income is denoted as $\mu(\boldsymbol{A})=n^{-1} \sum_{i} y_{i}^{\boldsymbol{A}}$. In the standard framework, $z_{i}^{\boldsymbol{A}}=\mu(\boldsymbol{A})$ for all individuals, 
whereas a more general framework allows for individual-specific fair incomes. However, we assume that for any $\boldsymbol{A}, \sum_{i} y_{i}^{\boldsymbol{A}}=\sum_{i} z_{i}^{\boldsymbol{A}}$, i.e., the distribution of fair incomes reflects a perception of how total income in society should be distributed. Thus, the set of possible alternatives to consider is given by

$$
\Xi=\left\{\boldsymbol{A} \mid z_{i}^{\boldsymbol{A}} \geq 0 \text { for all } i \text { and } \sum_{i} y_{i}^{\boldsymbol{A}}=\sum_{i} z_{i}^{\boldsymbol{A}}\right\}
$$

The standard Lorenz curve, $\mathbf{L}(s ; \boldsymbol{A})$, is constructed by ranking individuals according to their actual income, $y_{1(\boldsymbol{A})} \leq y_{2(\boldsymbol{A})} \leq \cdots \leq y_{n(\boldsymbol{A})}$, where $y_{1(\boldsymbol{A})}$ is the person with the lowest actual income in $\boldsymbol{A}$, and so on. However, the standard Lorenz curve can equally well be constructed by ranking the individuals according to how unfairly they have been treated, where unfairness is defined as the distance between the fair income and the actual income, $u_{i}^{\boldsymbol{A}}=y_{i}^{\boldsymbol{A}}-z_{i}^{\boldsymbol{A}} \cdot{ }^{1}$

In this framework the standard Lorenz curve can be written as follows:

$$
\mathbf{L}(s ; \boldsymbol{A})=\frac{\sum_{i=1}^{\lfloor n s\rfloor} y_{i(\boldsymbol{A})}}{n \mu(\boldsymbol{A})}=\frac{\sum_{i=1}^{\lfloor n s\rfloor} u_{i(\boldsymbol{A})}}{n \mu(\boldsymbol{A})}+s, \quad 0 \leq s \leq 1, z_{i}^{\boldsymbol{A}}=\mu(\boldsymbol{A}) \text { for all } i .
$$

Given that the second part of equation (1) only is a normalization and does not affect the comparison of any two Lorenz curves, it follows that the standard approach can be defined on cumulative shares of the distance between the average income and the actual income. The two different representations of the standard Lorenz curve are shown graphically in Figure 1.

[Figure 1 about here.]

This approach can be generalized to other fairness principles, where the unfairness Lorenz curve formally is defined as follows:

$$
\mathbf{L}^{\mathbf{U}}(s ; \boldsymbol{A})=\frac{\sum_{i=1}^{\lfloor n s\rfloor} u_{i(\boldsymbol{A})}}{n \mu(\boldsymbol{A})}, \quad 0 \leq s \leq 1, z_{i}^{\boldsymbol{A}} \geq 0 \text { for all } i .
$$

In the unfairness Lorenz curve, individuals are ordered according to how unfairly

\footnotetext{
${ }^{1} \mathrm{~A}$ formulation of unfairness in relative terms, $u_{i}^{\boldsymbol{A}}=\frac{y_{i(\boldsymbol{A})}}{z_{i}^{\mathbf{A}}}$, is not consistent with the requirement that $\sum_{i} u_{i}^{A}=0$.
} 
they are treated, such that $u_{1(\boldsymbol{A})} \leq u_{2(\boldsymbol{A})} \leq \cdots \leq u_{n(\boldsymbol{A})}$, which in general is not equivalent to ordering individuals by actual incomes.

The focus on unfairness Lorenz curves can be justified in exactly the same manner as in the standard case. Let us impose the following modified versions of the standard conditions on an inequality partial ordering defined on the alternatives in $\Xi$, where $\boldsymbol{A} \preceq \boldsymbol{B}$ represents that there is at least as much unfairness in $\boldsymbol{B}$ as in $\boldsymbol{A}$.

Definition 1. Scale Invariance: For any $a>0$ and $\boldsymbol{A}, \boldsymbol{B} \in \Xi$, if $\boldsymbol{A}=a \boldsymbol{B}$, then $\boldsymbol{A} \sim \boldsymbol{B}$

Definition 2. Anonymity: For any permutation function $\rho: \boldsymbol{N} \rightarrow \boldsymbol{N}$ and for $\boldsymbol{A}, \boldsymbol{B} \in \Xi$, if $\left(y_{i}^{\boldsymbol{A}}, z_{i}^{\boldsymbol{A}}\right)=\left(y_{\rho(i)}^{\boldsymbol{B}}, z_{\rho(i)}^{\boldsymbol{B}}\right)$ for all $i \in \boldsymbol{N}$, then $\boldsymbol{A} \sim \boldsymbol{B}$.

Definition 3. Generalized Pigou-Dalton: For any $\boldsymbol{A}, \boldsymbol{B} \in \Xi$, where $z_{i}^{\boldsymbol{A}}=z_{i}^{\boldsymbol{B}}$ for all $i$, if there exist $j, k$ such that $u_{j}^{\boldsymbol{A}}<u_{j}^{\boldsymbol{B}} \leq u_{k}^{\boldsymbol{B}}<u_{k}^{\boldsymbol{A}}$ and $u_{i}^{\boldsymbol{A}}=u_{i}^{\boldsymbol{B}}$ for all $i \neq j, k$, and $y_{j}^{\boldsymbol{B}}-y_{j}^{\boldsymbol{A}}=y_{k}^{\boldsymbol{A}}-y_{k}^{\boldsymbol{B}}$, then $\boldsymbol{A} \succ \boldsymbol{B}$.

Definition 4. Unfairism: For any $\boldsymbol{A}, \boldsymbol{B} \in \Xi$ such that $\mu(\boldsymbol{A})=\mu(\boldsymbol{B})$, if $u_{i}^{\boldsymbol{A}}=u_{i}^{\boldsymbol{B}}$ for all $i \in \boldsymbol{N}$, then $\boldsymbol{A} \sim \boldsymbol{B}$.

Scale invariance states that if all actual incomes and fair incomes are rescaled with the same factor, then the level of unfairness remains the same. Anonymity states that the ranking of alternatives should be unaffected by a permutation of the identity of individuals. The generalized version of the Pigou-Dalton criterion states that any fixed transfer of income from a person who is less unfairly treated to a person who is more unfairly treated reduces the level of unfairness. Finally, unfairism states that we are only concerned with how unfairly each person is treated, defined as the absolute deviation from the fair income of the individual.

In line with the standard approach, we define the unfairness Lorenz Dominance $\left(\mathbf{L} \mathbf{D}^{u}\right)$ as follows:

Definition 5. Unfairness Lorenz dominance: For any $A, B \in \Xi, A \mathbf{L D}^{u} \boldsymbol{B}$ if and only if $\sum_{i=1}^{\lfloor n s\rfloor} u_{i(\boldsymbol{A})}^{\boldsymbol{A}} / n \mu(\boldsymbol{A}) \geq \sum_{i=1}^{\lfloor n s\rfloor} u_{i(\boldsymbol{B})}^{\boldsymbol{B}} / n \mu(\boldsymbol{B})$ for all $0 \leq s \leq 1$, and there exists $s$ such that $\sum_{i=1}^{\lfloor n s\rfloor} u_{i(\boldsymbol{A})}^{\boldsymbol{A}} / n \mu(\boldsymbol{A})>\sum_{i=1}^{\lfloor n s\rfloor} u_{i(\boldsymbol{B})}^{\boldsymbol{B}} / n \mu(\boldsymbol{B})$. 
We now note that, as an analogue to the standard framework, unfairness Lorenz dominance is equivalent to a strict ranking of the alternatives for any partial ordering that satisfies the basic conditions.

Observation 1. For any partial inequality ordering on $\Xi$ satisfying Scale Invariance, Anonymity, Generalized Pigou-Dalton and Unfairism: If $\boldsymbol{A} \mathrm{LD}^{u} \boldsymbol{B}$, then $\boldsymbol{A} \prec \boldsymbol{B}$.

The proof of the observation is provided in the Appendix.

In this framework, it is also straightforward to modify the standard inequality measures. In our empirical analysis, we focus on the most common of these, namely the Gini, where the unfairness version is defined as

$$
\mathbf{G}^{u}(\boldsymbol{A})=\frac{1}{2 n(n-1) \mu(\boldsymbol{A})} \sum_{i} \sum_{j}\left|u_{i}^{\boldsymbol{A}}-u_{j}^{\boldsymbol{A}}\right| .
$$

We study cases where $y_{i} \geq 0$ for all individuals, and thus it follows that the unfairness Gini has a maximum value of $2 .^{2}$ It reaches its maximum when the actual income for all individuals except one is zero, and the fair income of the person who has all the income is zero and the fair income for one of the individuals with zero income is the total income in the economy. As illustrated in Figure 1, the unfairness Gini is represented by the area between the unfairness Lorenz curve and the horizontal axis. In the case where everyone's fair income is equal to the average income, the unfairness Gini equals the standard Gini.

\section{What is the fair income distribution?}

In order to measure the extent of unfairness in a given situation, we need to specify a principle of fairness that determines what would have been the fair distribution of income in this situation. We are concerned with fairness principles that are responsibility-sensitive in the sense that they justify inequalities due to responsibility

\footnotetext{
${ }^{2}$ For computational purposes, a simpler formulation of the unfairness Gini is given by $G^{u}(\boldsymbol{A})=$ $\frac{2}{n(n-1) \mu(\boldsymbol{A})} \sum_{i} i u_{i(\boldsymbol{A})}$.
} 
factors, but do not justify inequalities due to non-responsibility factors (Arneson, 1989; Cohen, 1989; Roemer, 1996, 1998).

For any given responsibility cut, i.e., a partition of the set of pre-tax income determinants into factors for which an individual is and is not responsible, the pretax income of an individual, $i$, can be written as $f\left(\boldsymbol{x}_{i}^{R}, \boldsymbol{x}_{i}^{N R}\right)$, where $\boldsymbol{x}_{i}^{R}$ and $\boldsymbol{x}_{i}^{N R}$ represent the vector of responsibility and non-responsibility factors respectively. ${ }^{3}$ A responsibility-sensitive fairness principle needs to address two questions. First, how should an individual's fair income, $z_{i}$, depend on the vector of responsibility factors, $\boldsymbol{x}_{i}^{R}$ ? Second, where should the cut between $\boldsymbol{x}_{i}^{R}$ and $\boldsymbol{x}_{i}^{N R}$ be drawn? The two questions are discussed separately below.

\subsection{A responsibility-sensitive fairness principle}

The classical proportionality principle is a well-known responsibility-sensitive fairness principle, where income is distributed in proportion to each individual's claim and where the claim is given by the value of the factor for which the individual is responsible. For example, if we assume that the number of working hours is the only responsibility factor, then a person's claim is equal to the number of hours worked. In this case, the classical proportionality principle assigns to each individual a share of the total income that is equal to his share of the total number of hours worked.

In this paper we apply a generalized version of the classical proportionality principle, as developed in Bossert (1995), Cappelen and Tungodden (2007), and Konow (1996). The generalized proportionality principle holds that an individual's claim is given by what would have been the average income in a hypothetical situation where everyone had the same responsibility vector as this individual. Hence, an individual's claim depends on the non-responsibility factors of all the individuals in the economy, but only on the individual's own responsibility factors.

The claim of individual $i, g\left(\boldsymbol{x}_{i}^{R} ; \cdot\right)$, can be written as

$$
g\left(\boldsymbol{x}_{i}^{R} ; \cdot\right)=\frac{1}{n} \sum_{j} f\left(\boldsymbol{x}_{i}^{R}, \boldsymbol{x}_{j}^{N R}\right) .
$$

\footnotetext{
${ }^{3}$ Here, and in the following, we suppress the notation $\boldsymbol{A}$ for an alternative.
} 
Individual $i$ 's fair income is then given by,

$$
z_{i}=\frac{g\left(\boldsymbol{x}_{i}^{R} ; \cdot\right)}{\sum_{j} g\left(\boldsymbol{x}_{j}^{R} ; \cdot\right)} \sum_{i} y_{i} .
$$

The generalized proportionality principle treats all individuals as if they were identical with respect to all non-responsibility factors. The principle can be said to be egalitarian because it eliminates all inequalities arising from non-responsibility factors, i.e., unfair inequality. The generalized proportionality principle can also be said to be responsibility-sensitive because it preserves inequalities that are only arising from responsibility factors, i.e., fair inequality.

The general proportionality principle satisfies the classical minimal requirements of unfair inequality elimination and fair inequality preservation proposed by Bossert and Fleurbaey (1996). First, any two individuals with the same responsibility factors are assigned the same fair income. Second, in any situation where all individuals have the same non-responsibility factors, each individual's fair income is equal to his pre-tax income. ${ }^{4}$

In the simple case where each individual's average productivity is constant and there is only one responsibility factor, the generalized proportionality principle is identical to the classical proportionality principle. In other economic environments, the classical proportionality principle is questionable. First, it sometimes justifies redistribution even if all individuals have the same non-responsibility factor, that is, the classical proportionality principle violates the minimal requirement of fair inequality preservation. Second, it is not well-defined in situations with more than one responsibility factor.

In sum, we consider the generalized proportionality principle an attractive formalization of a responsibility-sensitive fairness principle. There are other responsibility-sensitive fairness principles that satisfy both the minimal require-

\footnotetext{
${ }^{4}$ Interestingly, it can be shown that the generalized proportionality principle also satisfies a stronger, and attractive, general interpretation of fair inequality preservation, which extends the minimal requirement of fair inequality preservation to situations where people differ in nonresponsibility factors (Cappelen and Tungodden, 2007). In fact, it turns out that a complete characterization of the generalized proportionality principle can be made based on the strong requirement of fair inequality preservation and a rather weak requirement of unfair inequality elimination.
} 
ment of unfair inequality elimination and the minimal requirement of fair inequality preservation (Fleurbaey, 2008), and we consider three such alternatives in Section 6: two versions of the egalitarian equivalent principle and the conditional egalitarian principle.

\subsection{Drawing the responsibility cut}

In the philosophical literature, a prominent response to the question of where to draw the responsibility cut has been that individuals should be held responsible for factors under their control, but not for factors beyond their control (Cohen, 1989). However, other views, such as meritocratism, can be seen as holding individuals responsible for all personal factors, even genetic factors, independently of whether these factors are under individual control or not, and there is some experimental evidence indicating that this position is more prevalent in the population (Cappelen et al., 2007).

We take a pragmatic view on where the responsibility cut should be drawn, where we leave aside the question of how a particular responsibility cut should be justified. Instead we analyze the implications of various responsibility cuts and leave it to the reader to determine which of these is more appealing.

Nonetheless, to simplify the presentation, we begin by focusing on the responsibility cut where a person is held responsible for the number of hours worked, years of education, whether he or she works in the public or private sector, and his or her county of residence, whereas the person is not held responsible for the field of education, age and gender. We do not make the claim that this is the correct responsibility set, and later we analyze the implications of expanding and reducing the responsibility set and of controlling for family background and innate ability for a subsample of the population.

Clearly, the implications of the generalized proportionality principle strongly depend on which factors are included in the responsibility set. To illustrate, if individuals are not held responsible for any factors, then the principle implies that the fair income distribution is to give everyone an equal share of total income. On 
the other hand, if individuals are held responsible for all factors, then it implies that the fair income distribution is given by the pre-tax income distribution.

In an empirical analysis we need to address the specific question of how to treat the unobservable factors that affect a person's pre-tax income. In the main part of this paper we respond to this question by appealing to the basic egalitarian intuition that deviations from an equal distribution can only be justified if individuals differ with respect to some responsibility factors. In principle, some of the unobservable factors may be responsibility factors, but it is not possible to determine whether individuals differ with respect to these factors. We therefore find it attractive to treat all unobservable factors as non-responsibility factors. However, for the sake of completeness, we also consider the implications of including the unobservable factors in the responsibility set.

\section{Descriptive statistics}

We apply our framework to study the pre-tax income distribution in Norway in the period from 1986 to 2005. In this section we describe the data and the estimation of the labor earnings equation.

\subsection{Data}

We use a database constructed at the Norwegian School of Economics and Business Administration based on administrative records collected by Statistics Norway (Møen, Salvanes, and Sørensen, 2003). In these records, information on individuals is collected using a unique personal identifier that makes it possible to link data collected for various administrative purposes.

Our measure of pre-tax income is annual labor earnings. ${ }^{5}$ It includes all earnings from work activities, but excludes pensions, transfers that are not direct replacements of labor income, and any capital income. ${ }^{6}$ However, it includes temporary

\footnotetext{
${ }^{5}$ This is also the measure on which the contributions to National Insurance are calculated.

${ }^{6}$ Capital income is excluded from the analysis because it is difficult to get reliable data on capital income in Norway. The data on capital income are of low quality in Norway primarily because most people have their wealth invested in the house where they live. A large fraction of
} 
sick-leave benefits and unemployment benefits. A tax reform in 1992 made income from self-employment part of this definition of labor earnings. This change affected the upper tail of the labor earnings distribution (and increased the variance of labor earnings), but given the relatively small number of self-employed individuals, it barely had any impact on the measured inequality.

We deflate all the labor earnings to 1998 prices using the Consumer Price Index constructed by Statistics Norway. The number of hours worked in a normal week are also reported by employers to the National Insurance authorities as indicator variables for "less than 20 hours a week", "20 to 30 hours a week", and "more than 30 hours a week", and we use this to measure the number of hours worked. Schooling is taken from a national database of education completed, and includes data from the 1970 census and onwards (Vassenden, 1995).

We restrict the analysis to persons with complete data on demographics and education. We also restrict ourselves to those for whom we observe non-zero annual labor earnings and with reported hours of work at the time of observation, end of May 1986-1994 and end of November 1995-2005. In doing so, we not only remove those out of the labor force due to unemployment, disability, or some other reason, but also the self-employed and those working in companies not complying with the reporting guidelines. By far the most important restriction is that we restrict ourselves to persons with reported hours of work. In 1986, $27 \%$ of all men and $35 \%$ of women had no reported hours of work, while these same figures in 2005 were $26 \%$ and $29 \%$. The other restrictions only remove a couple of additional percentage points, and this is constant over the period. Summing up, the restrictions make men slightly more represented in the analysis (as shown in Table 1).

[Table 1 about here.]

For parts of the analysis, we work with the subsample of the population for which

capital income is thus the gain from owning your own house and this gain is difficult to calculate as the value of houses are poorly registered. Furthermore, in order for capital income to add to the understanding of unfairness we would need to partition the set of capital income determinants into factors for which an individual is, and is not, responsible. It could, for example, be argued that people should be held responsible for how much they save, but not be held responsible for their inheritance. Information about the determinants of capital income is, however, not contained in any data set that we are aware of. 
we have family background variables. Family background variables are only available when identification of parents is available in the central population register. This was not established until 1964, but was in part based on the census of 1960 (Skaug, 1968). Hence, for the older cohorts, there is only limited information available on family background. For this reason we limit this subsample to those born in 1946 or later, who were mostly living with their parents in the 1960 census. For the 1986 sample, we are able to match the education of both parents and the county in which they lived in the 1960 census for 68\% of these cohorts (332 240 individuals), in the 2005 sample we can match these variables for 86\% of the cohorts (1 153781 ) individuals.

For another subsample, we are able to use a direct IQ measure obtained from military records. All male, and some female, citizens undergo a medical examination at 17-18 years, intended to determine their fitness for military service. As part of this examination, there is a classification of their ability score in Standard Nine (stanine) units, which is a method of standardizing raw scores into a nine point standard scale with a normal distribution, a mean of 5 , and a standard deviation of 2. This data is available for persons being examined from 1968 onwards (see also Black, Devereux, and Salvanes (2007)). For the 1986 sample, we are able to match the full set of family background and the IQ score for $44 \%$ of the male cohorts born after 1946 (111 533 individuals), in the 2005 sample we can match everything for $72 \%$ of the male cohorts (497 222 individuals).

\subsection{The labor earnings equation}

Table 1 presents some descriptive statistics on education and labor earnings, where the main observation is that there are no major structural changes between 1986 and 2005. The most important change in the period is captured in Table 2, which shows the composition of hours worked, the proportion working in the public sector and years of education, all broken down by gender. We observe that there has been a substantial increase in the proportion of females working more than 30 hours a week. It is also interesting to note that while in 2005 males and females, on average, 
have the same years of education, females work to a much greater extent in the public sector.

[Table 2 about here.]

We use a linear model of the logarithm of labor earnings,

$$
\log y_{i}=\boldsymbol{\beta} \boldsymbol{x}_{i}^{R}+\boldsymbol{\gamma} \boldsymbol{x}_{i}^{N R}+\varepsilon_{i}
$$

where $\boldsymbol{x}_{i}^{R}$ are the explanatory variables for which $i$ is to be held responsible, $\boldsymbol{x}_{i}^{N R}$ are the explanatory variables for which $i$ is not held responsible, and $\varepsilon_{i}$ captures unobservable factors. To focus on our main research question, we make the assumption that $\varepsilon_{i}$ is independent of $\boldsymbol{x}_{i}=\left(\boldsymbol{x}_{i}^{R}, \boldsymbol{x}_{i}^{N R}\right)$.

Table 3 shows the regression results for 1986 and 2005. We observe that the estimated effect of working more than 30 hours slightly decreases during the period, whereas the return for the group working between 20 and 30 hours slightly increases. In 2005, working more than 30 hours almost doubled the estimated labor earnings compared to working less than 20 hours.

[Table 3 about here.]

The estimated coefficients on years of education are in line with previous studies, both on international and Norwegian data (Belzil, 2007; Hægeland, Klette, and Salvanes, 1999). We also observe that both these estimates and the estimates on the types of education are almost constant during the period. In contrast, there is a substantial decrease in the estimated effect of gender. All else being equal, in 2005, the labor earnings of females are $78 \%$ of the labor earnings of men, while in 1986 these earnings are $68 \%$ of those of men. Keeping in mind that most females work in the public sector, as shown in Table 2, it is also interesting to observe that being employed in the public sector has a substantial negative effect on labor earnings in 2005, even after controlling for types of education, while there was no such effect present in the estimates for 1986. Finally, we observe that there is an increase in the estimated effect of age. 


\section{Pre-tax income unfairness}

Has the pre-tax income distribution in Norway become more or less fair in the period 1986 to 2005? To address this question we estimate the fair income distribution, and then use it to measure the development of the unfairness Gini in this period.

\subsection{The fair income distribution}

Simple algebraic substitution using (5) and (6) provides the following expression of the estimated fair income for each individual: ${ }^{7}$

$$
z_{i}=\frac{\exp \left(\boldsymbol{\beta} \boldsymbol{x}_{i}^{R}\right)}{\sum_{j} \exp \left(\boldsymbol{\beta} \boldsymbol{x}_{j}^{R}\right)} \sum_{j} y_{j}
$$

Individuals with different responsibility vectors may obviously have different fair incomes. To illustrate, it follows from the estimated labor earnings equation that the highest fair income in 2005 was close to five times as high as the lowest fair income. Overall, fair inequality, measured as the difference between the fair income distribution and perfect equality, decreased slightly over the period. The standard Gini for the fair income distribution fell from 0.176 in 1986 to 0.149 in 2005.

Differences in hours worked justify much of the fair inequality, but other responsibility factors also play an important role. The labor earnings estimates for 2005 show that it may be fair to give one person two and a half times more income than another who worked the same number of hours if they differ maximally with respect to the other responsibility factors.

Figure 2 shows the cumulative distribution functions of fair incomes and labor earnings. As the cumulative distributions of fair income is steeper, less skewed, and concentrated in a smaller interval, we know that the actual distribution of labor earnings is less equal than the fair income distribution.

The general impression from a comparison of the cumulative distribution func-

$$
\begin{aligned}
&{ }^{7} \text { Let } C_{i}=\exp \left(\boldsymbol{\beta} \boldsymbol{x}_{i}^{R}\right) \text { and } D_{i}=\exp \left(\boldsymbol{\gamma} \boldsymbol{x}_{i}^{N R}+\varepsilon_{i}\right) \text {, so } f\left(\boldsymbol{x}_{i}, \varepsilon_{i}\right)=C_{i} D_{i} \text {. Then } \\
& g\left(\boldsymbol{x}_{i}^{R}\right) / \sum_{j} g\left(\boldsymbol{x}_{j}^{R}\right)=n^{-1} \sum_{j} C_{i} D_{j} /\left(\sum_{h} n^{-1} \sum_{j} C_{h} D_{j}\right)=C_{i} \sum_{j} D_{j} / \sum_{h} C_{h} \sum_{j} D_{j} .
\end{aligned}
$$

Since $\sum_{j} D_{j}$ is a constant, this simplifies to $C_{i} / \sum_{h} C_{h}$. 
tions is that the distance between labor earnings and fair incomes has increased from 1986 to 2005. However, cumulative distributions are not ordered on individuals, which is essential when fair incomes are individual specific. By way of illustration, consider a situation where there is no unfairness. In this case, the cumulative distribution functions and labor earnings would completely overlap. But suppose that we now permute the labor earnings distribution. This would leave the cumulative distribution function for labor earnings unchanged, but might induce a substantial amount of unfairness.

Therefore we present the maps shown in Figure 3, to show the extent to which each individual's labor earnings deviate from his fair income in 1986 and 2005. If all individuals received their fair income, then all observations should be on the diagonal line. All observations above the diagonal reflect individuals with a fair income that is higher than their labor earnings, whereas all observations below the diagonal represent individuals receiving labor earnings higher than their fair income. The darkest area indicates the highest density of people. We observe that there are some people having substantially higher labor earnings than their fair income, i.e. the lighter areas east in the diagram. There is also a group of people with a larger fair income than labor earnings, as indicated by the grey and light areas southwest in the diagram. Comparing 1986 and 2005, we observe that there are more observations further away from the diagonal in 2005, which indicates an increase in the unfairness of pre-tax income in Norway during this period.

[Figure 2 about here.]

[Figure 3 about here.]

\subsection{Measuring unfairness}

The impression that there has been an increase in pre-tax income unfairness is confirmed by Figure 4, which shows that there has been an increase in the unfairness Gini from 0.204 in 1986 to 0.220 in 2005. In contrast, the standard Gini for the labor earnings distribution decreased in the period from 0.270 to 0.262 . Hence, even 
though the changes are not large, we observe that the unfairness Gini provides a qualitatively different conclusion than the standard approach for the development of the pre-tax income distribution in Norway during this period.

[Figure 4 about here.]

What explains the diverging development of the standard Gini and the unfairness Gini? We study this question by conducting a Blinder-Oaxaca type decomposition (Blinder, 1973; Oaxaca, 1973), where we construct counterfactual incomes by interchanging characteristics, returns, and residuals for 1986 and 2005. ${ }^{8}$ Table 4 reports the aggregate results from this decomposition. Row (1) and row (7) report the standard Gini and the unfairness Gini in 1986 and 2005, whereas rows (2)-(6) report the standard Gini and the unfairness Gini for counterfactual income distributions generated by replacing one element from the 1986-distribution with the corresponding element from the 2005-distribution.

Comparing the standard Gini and the unfairness Gini in 1986 (row (1)) with rows (2)-(6), we observe that the change in the return on responsibility factors, $\boldsymbol{\beta}$, has the largest impact on both the standard Gini and the unfairness Gini. But the effect is the same for both measures, and thus cannot contribute to explain the divergent patterns. Neither can the changes in the return on the non-responsibility factors, $\gamma$, and in the residual, $\varepsilon$, since these changes only have marginal impact on both measures.

[Table 4 about here.]

The main explanations of the divergent patterns are that the overall changes in the composition of responsibility factors and of the non-responsibility factors do affect the two measures very differently. By comparing row (1) and row (5), we

\footnotetext{
${ }^{8}$ The counterfactual $\boldsymbol{\beta}$ and $\gamma$ are given by the estimates for 2005 . The counterfactual $\boldsymbol{x}^{R}$ is constructed by dividing the population into 1000 permillages, based on the distribution of $\boldsymbol{\beta} \boldsymbol{x}^{R}$. For each individual $j$, we then draw a random counterfactual $\overline{\boldsymbol{x}}_{j}^{R}$ from the distribution of $\boldsymbol{x}_{i}^{R}$ in the permillage in 2005 corresponding to the permillage this person belongs to in the distribution of $\boldsymbol{\beta} \boldsymbol{x}^{R}$ in 1986. We follow the same procedure for $\boldsymbol{\beta} \boldsymbol{x}^{N R}$ and for the disaggregated analysis of the responsibility and non-responsibility factors. Finally, the counterfactual $\varepsilon$ is constructed by dividing the population into 1000 permillages, based on the distribution of $\varepsilon_{i}$. For each individual $j$, we then draw randomly the counterfactual $\varepsilon_{j}$ from the permillage in 2005 corresponding to the permillage this person belongs to in the distribution of $\varepsilon_{i}$ in 1986.
} 
observe that the overall change in the composition of responsibility factors has no effect on the unfairness Gini, whereas the standard Gini falls from 0.270 to 0.261. By comparing row (1) and row (6) in Table 4, we observe that the overall change in the composition of non-responsibility factors causes a small decrease in the standard Gini but a substantial increase in the unfairness Gini.

Table 5 provides a more disaggregated picture of how the changes in the decomposition of responsibility and non-responsibility factors affect the development of the two measures. We observe that two important factors are related to the change in the situation of women. First, we observe that the increase in the share of females in the working force increases the unfairness Gini, whereas it has no impact on the standard Gini. Second, we observe that the change in the composition of hours worked, which mainly reflects a sharp increase in the share of women working more than 30 hours, contributes to a decrease in the standard Gini but an increase in the unfairness Gini. This effect is also illustrated in Figure 5, which shows that even though the average income of females is much closer to the average income in society in 2005, it is not much closer to the average fair income of females.

[Table 5 about here.]

This type of decomposition does not capture possible interaction effects among the various factors, for example that the combined change in the composition of nonresponsibility factors and responsibility factors may change the correlation between the income from responsibility factors and the income from non-responsibilty factors (Fleurbaey, 2008; Piketty, 1994). Interestingly, it turns out that there has been a large decrease in this correlation, from 0.27 in 1986 to 0.10 in $2005 .{ }^{9}$ This decrease reduces the standard Gini but has no impact on the unfairness Gini, and thus provides an additional explanation for the diverging pattern of the two measures.

[Figure 5 about here.]

\footnotetext{
${ }^{9}$ Income from responsibility factors and non-responsibility factors are defined as $\exp \left(\boldsymbol{\beta} \boldsymbol{x}_{i}^{R}\right)$ and $\exp \left(\boldsymbol{\gamma} \boldsymbol{x}_{i}^{N R}\right)$, where $\boldsymbol{\beta}$ and $\boldsymbol{\gamma}$ are estimated from (6).
} 


\subsection{Relocating the responsibility cut}

So far, we have assumed that people are held responsible for the number of hours worked, years of education, sector (public versus private) and county of residence. However, this choice is clearly controversial, and we now discuss the implications of alternative specifications of the responsibility set.

Table 6 shows the development of the unfairness Gini for different responsibility sets, and we observe that there is a striking difference between the standard approach and any responsibility-sensitive approach that only includes observable factors in the responsibility set. When comparing the data for 1986 and 2005, we observe a $3 \%$ decrease in the unfairness Gini when the responsibility set is empty (the standard approach), whereas for all other specifications of the responsibility set that we consider the unfairness Gini increases by about $6-12 \%$ in this period. The increase in unfairness is particularly large when people only are held responsible for the numbers of hours worked and years of education. In the last row in Table 6 we also consider a responsibility set that includes the non-observable factors. Not surprisingly, this contributes to a substantial reduction in measured unfairness. We also observe that the inclusion of the non-observable factors implies that overall unfairness has decreased substantially in Norway, the unfairness Gini drops by almost $40 \%$, which is mainly explained by the fact that unobservable variables are much more important in the labor earnings equation in 2005 than in 1986 (see the decrease in the $R^{2}$-value in Table 3$)$.

Some may find it curious that we have considered the possibility of including age in the responsibility set, given that this is clearly a factor that is beyond individual control. However, the inclusion of this factor can be justified on pragmatic grounds, and serves as an approximation of the view that our concerns should be equality in expected lifetime labor earnings. This was a primary argument in the early literature on fair income (Paglin, 1975), and it is still present in public debate. However, in our analysis, this is not a fundamental issue, since the unfairness Gini only changes slightly when including age in the responsibility set.

It is interesting to note that the unfairness Gini is not necessarily decreasing 
monotonically as the responsibility set expands. It is so for 2005, but not for 1986 . In 1986, we observe an increase in the unfairness Gini when we add the choice of working in the private or public sector to the responsibility set. The reason is that public employment in 1986 has a positive sign in the labor earnings equation. Females, who on average are more unfairly treated than males, are over-represented in this sector. To introduce responsibility for the choice of sector in 1986 implies, on average, an increase in the fair income of females, and consequently, an increase in unfair inequality. This illustrates the general point that deviation from the fair distribution may increase as we hold people responsible for more factors, and it may even be the case that a responsibility-sensitive framework reports more unfairness than the standard approach of no responsibility (even though this is not the case in our analysis; see Cappelen and Tungodden (2006)).

[Table 6 about here.]

\section{Robustness analysis}

In this section, we examine how robust our main findings are to the core elements in the framework, where our focus is on responsibility sets which only include observable factors.

\subsection{Innate ability and family background}

A fundamental concern in the application of responsibility-sensitive theories of justice is that the responsibility factors might be affected by non-responsibility factors (see for example Betts and Roemer (2007)). In our study, one may question whether hours worked and years of education are affected by non-responsible factors such as family background and innate ability. If so, one should control for these non-responsibility factors when holding people responsible.

Fortunately, we have data that allows us to study this issue in more detail. We start by considering how controlling for family background might affect our analysis. For a subsample we have information about family background, and thus we can 
run regressions of hours worked and years of education on these variables. These regressions show that, for this subsample, family background correlates with years of education, but not with hours worked. To control for family background when holding individuals responsible for years of education, we construct a new variable given by the difference between the actual years of education and the predicted years of education based on family background. Panel A in Table 7 reports how our estimates of the unfairness Gini for this subgroup is affected when years of education is replaced by this new variable in the responsibility set. We observe that the unfairness Gini is lower when controlling for family background. The effect, however, is rather small and almost identical for 1986 and 2005; for our main specification of the responsibility set, the unfairness Gini decreases with 0.01 in both years.

[Table 7 about here.]

We are also able to study how innate ability might affect our estimates. For a subsample of males we also have access to a direct measure of cognitive skills from military records. Again, for this subsample, the non-responsibility factors turn out to be of importance for years of education, but not for hours worked. However, as reported in Panel B in Table 7, there is only a very minor change in our estimates of unfairness when controlling both for innate ability and family background on years of education.

\subsection{Unfairness Lorenz dominance}

So far, our analysis has relied on the unfairness Gini, and thus it is interesting to study the extent to which other measures of unfairness support the same conclusion. Figure 6 shows the unfairness Lorenz curves for 1986 and 2005 for our main specification of the responsibility set, and we observe that there is no unfairness Lorenz dominance. The labor earnings of the most unfairly treated group is slightly closer to the fair income of this group in 2005 than it is in 1986, whereas the opposite is the case for the rest of the population. Moreover, we observe that there is a much greater difference between the two unfairness Lorenz curves for the upper tail of the 
distribution. Using all other non-empty responsibility sets (only including observable variables), we obtain similar patterns as in Figure $6 .{ }^{10}$ In each case, there is almost perfect overlap for the most unfairly treated group, and a marked difference for the rest of the population. Given the ordering of the responsibility sets reported in Table 6, the single crossing occurs at values of the percentiles of the population of $40.0,20.8,37.2,37.0,33.6$, and 38.2 , respectively.

[Figure 6 about here.]

The lack of unfairness Lorenz dominance implies that there exist other unfairness measures satisfying the basic conditions introduced in Section 2, that would go against the conclusion of the unfairness Gini. However, given that the unfairness Lorenz curves almost overlap for the most unfairly treated, such measures would have to assign very high priority to the lower tail of the unfairness distribution. We doubt that there is political support for such priority to the most unfairly treated, and thus for practical purposes we tend to conclude that our finding of increasing unfairness in Norway is robust to the choice of unfairness measure.

It is also interesting to compare the unfairness Lorenz curves to the standard Lorenz curves, i.e. unfairness Lorenz curves with an empty responsibility set. The standard Lorenz curves, which are shown in Figure 7, also have a single crossing, but they have a more marked difference for the most unfairly treated group. Consequently, the class of inequality measures that would indicate an increase in inequality from 1986 to 2005 is larger for the case of an empty responsibility set.

[Figure 7 about here.]

In sum, we conclude that our finding of increasing unfairness in the pre-tax income distribution in Norway is robust to the choice of unfairness measure, unless one endorses a strict egalitarian point of view or assigns extreme priority to the most unfairly treated.

\footnotetext{
${ }^{10}$ The figures for the other non-empty responsibility sets are available from the authors upon request.
} 


\subsection{Alternative responsibility-sensitive fairness principles}

The generalized proportionality principle provides an attractive formulation of the view that inequalities due to non-responsibility factors should be eliminated, while inequalities due to responsibility factors should be accepted. However, other responsibility-sensitive fairness principles have been proposed in the literature, and in this section, we study whether three alternatives, two versions of the egalitarian equivalent fairness principle and one version of the conditionally egalitarian fairness principle, give other results.

According to one version of the egalitarian equivalent fairness principle (Bossert and Fleurbaey, 1996), the fair income of individual $i$ is given by

$$
z_{i}^{E E}=f\left(\boldsymbol{x}_{i}^{R}, \widetilde{\boldsymbol{x}}^{N R}\right)+C^{E E}
$$

where $\widetilde{\boldsymbol{x}}^{N R}$ is a reference non-responsibility vector, and $C^{E E}$ is a constant such that the average fair income is equal to the average pre-tax income. We focus in the empirical analysis on the case were each element in the reference non-responsibility vector is defined by the average value of the corresponding non-responsibility factor in society.

Within the egalitarian equivalent framework, an alternative formulation of the idea that people's fair income should depend on the average non-responsibility vector in society is given by

$$
z_{i}^{\overline{E E}}=\frac{1}{n} \sum_{j} f\left(\boldsymbol{x}_{i}^{R}, \boldsymbol{x}_{j}^{N R}\right)+C^{\overline{E E}}
$$

where $C^{\overline{E E}}$ is a constant that ensures that the average fair income is equal to the average pre-tax income.

Finally, another prominent responsibility-sensitive fairness principles is the conditional egalitarian fairness principle (Kolm, 1996), where the fair income of individual $i$ is given by

$$
z_{i}^{C E}=f\left(\boldsymbol{x}_{i}^{R}, \boldsymbol{x}_{i}^{N R}\right)-f\left(\widetilde{\boldsymbol{x}}^{R}, \boldsymbol{x}_{i}^{N R}\right)+C^{C E},
$$


where $\widetilde{x}^{R}$ is the reference responsibility vector and $C^{C E}$ is a constant equal to what would have been the average income in the economy if everyone had responsibility factors described by the reference responsibility vector. We focus in the empirical analysis on the case were each element in the reference responsibility vector is the average value of the corresponding responsibility factor in society.

[Figure 8 about here.]

Figure 8 shows the development of the unfairness Gini for each of the four fairness principles. We observe that the four approaches report the same trend. The generalized proportionality fairness principle and the two formulations of the equalitarian equivalent principle have almost identical implications; in fact, the generalized proportionality principle and the alternative formulation of the egalitarian equivalent principle cannot be distinguished in the figure. The conditional egalitarian principle implies a lower overall level of unfairness, which reflects that this approach is only truly egalitarian at the reference responsibility level. But also this fairness principle supports our main finding of increasing unfairness in the pre-tax income distribution in Norway.

\section{Post-tax income unfairness}

We now turn to a study of the unfairness in the post-tax income distribution, which is interesting on two accounts. First, in welfare studies, we are interested in the final outcome for individuals. Second, by comparing pre-tax and post-tax unfairness, we can gain insight into whether the Norwegian tax system contributes to reduced unfairness.

We do not have reliable data on post-tax income that we can use to estimate post-tax inequality and post-tax unfairness directly. However, by using a model that captures the main features of the Norwegian income tax system in 1986 and 2005, we are able to impute post-tax incomes. ${ }^{11}$ Based on these imputations, we

\footnotetext{
${ }^{11}$ Details of the tax model can be found on http://thomas.nhh.no/stata/norsk_skatt.html.
} 
estimate the corresponding measures of the standard Gini and the unfairness Gini for the post-tax income distribution.

Table 8 shows that there has been an even greater increase in the post-tax unfairness in the period. For our main specification of the responsibility set, the unfairness Gini increases with $16.5 \%$ in the post-tax income distribution, compared to an increase of $7.8 \%$ in the pre-tax income distribution. The increase in unfairness Gini is also much greater than the increase in post-tax inequality. The standard Gini increases with $6.8 \%$, whereas all versions of the unfairness Gini increases with at least $16.5 \%$.

Does the Norwegian income tax system contribute to reduced unfairness? A progressive tax system may have two opposing effects on unfairness. First, it may reduce unfair inequalities between individuals who are identical with respect to their responsibility factors. Second, it may eliminate fair inequalities between individuals who differ with respect to their responsibility factors. The first effect contributes to reduced unfairness, whereas the second effect contributes to increased unfairness. We observe, by comparing Table 6 and Table 8, that the overall effect of the Norwegian income tax system is a reduction in unfairness both in 1986 and 2005. However, we also observe that the overall effect is larger in 1986 than in 2005; for our main specification of the responsibility set, the tax system reduces the unfairness Gini with $22.6 \%$ in 1986 and $16.6 \%$ in 2005 . Hence, the tax reforms in Norway between 1986 and 2005 have made the tax system less capable of reducing overall unfairness, which explains why there has been a larger increase in unfairness in the post-tax income distribution than in the pre-tax income distribution. These reforms have also reduced the progressivity of the tax system, which explains why the reduction in the standard Gini is much lower in 2005 than in 1986.

[Table 8 about here.] 


\section{Concluding remarks}

In this paper we have generalized the standard approach to inequality measurement, where we allow for different interpretations of what is a fair income distribution. Within the generalized framework, we have estimated the fair income distribution in Norway from 1986 to 2005, and measured the unfair (in)equality during the same period. Interestingly, when studying the pre-tax income distribution, we find that even though the standard Gini is lower in 2005 than in 1986, there is an overall increase in unfairness. This finding is robust to changes in the responsibility set (as long as we do not hold people responsible for unobservable factors) and to alternative formulations of the unfairness measure and the underlying responsibility-sensitive fairness principle. We furthermore find that the Norwegian tax system contributes to a reduction in overall unfairness, but less so in 2005. Consequently, the increase in post-tax unfairness is even greater than in the pre-tax income distribution.

We believe that our findings illustrate the importance of incorporating the distinction between fair and unfair inequalities in empirical inequality studies, and we think that the approach proposed in this paper provides one promising framework for such analyzes. Another interesting avenue for future research would be to apply the theoretical framework suggested by Fleurbaey and Maniquet (2006), who focus more directly on holding people responsible for their preferences. A challenge to this approach, however, is that it relies on estimating the distribution of individual preferences in the population, which is a difficult task given the standard types of data available.

\section{References}

Arneson, Richard (1989). "Equality and equal opportunity for welfare", Philosophical Studies, 56(1): 159-194.

Belzil, Christian (2007). "The return to schooling in structural dynamic models: a survey", European Economic Review, 51(5): 1059-1105. 
Betts, Julian R. and John E. Roemer (2007). "Equalizing opportunity for racial and socioeconomic groups in the United States through educational-finance reform", in "Schools and the Equal Opportunity Problem", (edited by Ludger Woessmann and Paul E. Peterson), chapter 9, CESifo Seminar Series, MIT Press, (pp. 209237).

Black, Sandra E., Paul J. Devereux, and Kjell G. Salvanes (2007). "Small family, smart family? Family size and the IQ scores of young men", NBER Working Paper No. 13336.

Blinder, Alan S. (1973). "Wage discrimination: Reduced form and structural estimates", Journal of Human Resources, 8(4): 436-455.

Bossert, Walter (1995). "Redistribution mechanisms based on individual characteristics", Mathematical Social Sciences, 29(1): 1-17.

Bossert, Walter and Marc Fleurbaey (1996). "Redistribution and compensation", Social Choice and Welfare, 13(3): 343-355.

Bourguignon, François, Francisco H. G. Ferreira, and Marta Menéndez (2007). "Inequality of opportunity in Brazil", Review of Income and Wealth, 53(4): 585-618.

Cappelen, Alexander and Bertil Tungodden (2006). "Relocating the responsibility cut: Should more responsibility imply less redistribution", Politics, Philosophy and Economics, 5(3): 353-362.

Cappelen, Alexander and Bertil Tungodden (2007). "Fairness and the proportionality principle", Discussion paper SAM 31/2007, Norwegian School of Economics and Business Administration.

Cappelen, Alexander W., Astri Drange Hole, Erik Ø. Sørensen, and Bertil Tungodden (2007). "The pluralism of fairness ideals: An experimental approach", American Economic Review, 97(3): 818-827.

Cohen, G. A. (1989). "On the currency of egalitarian justice", Ethics, 99(4): 906944. 
Devooght, Kurt (2008). "To each the same and to each his own. A proposal to measure responsibility-sensitive income inequality", Economica, 75(298): 280295.

Fleurbaey, Marc (1995). "Equality and responsibility", European Economic Review, 39(3-4): 683-689.

Fleurbaey, Marc (2008). Fairness, Responsibility, and Welfare, Oxford, UK: Oxford University Press.

Fleurbaey, Marc and Francois Maniquet (2006). "Fair income tax", Review of Economic Studies, 73(1): 55-82.

Frohlich, Norman, Joe Oppenheimer, and Anja Kurki (2004). "Modeling otherregarding preferences and an experimental test", Public Choice, 119(1-2): 91-117.

Gaertner, Wulf and Lars Schwettmann (2007). "Equity, responsibility and the cultural dimension", Economica, 74(296): 627-649.

Hægeland, Torbjørn, Tor Jakob Klette, and Kjell G. Salvanes (1999). "Declining returns to education in Norway? Comparing estimates across cohorts, sectors and time", Scandinavian Journal of Economics, 101(4): 555-576.

Kolm, Serge-Christophe (1996). Modern Theories of Justice, Cambridge, MA: MIT Press.

Konow, James (1996). "A positive theory of economic fairness", Journal of Economic Behavior and Organization, 31(1): 13-35.

Konow, James (2000). "Fair shares: Accountability and cognitive dissonance in allocation decisions", American Economic Review, 90(4): 1072-1091.

Møen, Jarle, Kjell G. Salvanes, and Erik Ø. Sørensen (2003). "Documentation of the linked employer-employee dataset at Norwegian School of Economics", mimeo, Norwegian School of Economics. 
Oaxaca, Ronald (1973). "Male-female wage differentials in urban labor markets", International Economic Review, 14(3): 693-709.

Paglin, Morton (1975). "The measurement and trend of inequality: A basic revision", American Economic Review, 65(4): 598-609.

Piketty, Thomas (1994). "Existence of fair allocations in economies with production", Journal of Public Economics, 55(3): 391-405.

Roemer, John E. (1996). Theories of Distributive Justice, Cambridge, MA: Harvard University Press.

Roemer, John E. (1998). Equality of Opportunity, Cambridge, MA: Harvard University Press.

Roemer, John E., Rolf Aaberge, Ugo Colombino, Johan Fritzell, Stephen P. Jenkins, Ive Marx, Marianne Page, Evert Pommer, Javier Ruiz-Castillo, Maria Jesus San Segundo, Torben Tranaes, Gert G. Wagner, and Ignacio Zurbiri (2003). "To what extent do fiscal systems equalize opportunities for income acquisition among citizens?", Journal of Public Economics, 87(3-4): 539-565.

Schokkaert, Erik and Kurt Devooght (2003). "Responsibility-sensitive fair compensation in different cultures", Social Choice and Welfare, 21(2): 207-242.

Skaug, Helge (1968). "Oversikt over det sentrale personregister i statistisk sentralbyrå", Artikler fra Statistisk sentralbyrå 22 .

Vassenden, Elisabetta (1995). "The register of the level of education: a product of the integration of other registers, census and surveys", Statistisk sentralbyrå, Notater 95/4. 


\section{Appendix A Proof of observation}

Proof. Consider any $\widehat{\boldsymbol{A}}, \widehat{\boldsymbol{B}} \in \Xi$, where $\widehat{\boldsymbol{A}} \mathbf{L D}^{u} \widehat{\boldsymbol{B}}$. We will now show that $\widehat{\boldsymbol{A}} \prec \widehat{\boldsymbol{B}}$ for any partial ordering satisfying the conditions stated in the observation.

(i) Consider $\boldsymbol{A}, \tilde{\boldsymbol{B}} \in \Xi$, where $\left(y_{i}^{\boldsymbol{A}}, z_{i}^{\boldsymbol{A}}\right)=\left(y_{i(\widehat{\boldsymbol{A}})}, z_{i(\widehat{\boldsymbol{A}})}\right)$ and $\left(y_{i}^{\tilde{\boldsymbol{B}}}, z_{i}^{\tilde{\boldsymbol{B}}}\right)=\left(y_{i(\widehat{\boldsymbol{B}})}, z_{i(\widehat{\boldsymbol{B}})}\right)$ for all $i \in \boldsymbol{N}$. By Anonymity, $\boldsymbol{A} \sim \widehat{\boldsymbol{A}}$ and $\tilde{\boldsymbol{B}} \sim \widehat{\boldsymbol{B}}$. Moreover, consider $\boldsymbol{B} \in \Xi$, where $\boldsymbol{B}=(\mu(\widehat{\boldsymbol{A}}) / \mu(\widehat{\boldsymbol{B}})) \tilde{\boldsymbol{B}}$. By Scale Invariance, $\boldsymbol{B} \sim \tilde{\boldsymbol{B}}$.

(ii) By (i), $\boldsymbol{A} \mathbf{L D}^{u} \boldsymbol{B}$. Hence, it follows that $u_{1(\boldsymbol{A})} \geq u_{1(\boldsymbol{B})}$. Consider now the following sequence:

$$
\begin{aligned}
\boldsymbol{A}_{1}= & \boldsymbol{A} \\
\boldsymbol{A}_{2}= & \left(y_{1}^{\boldsymbol{A}}-\min \left\{u_{1(\boldsymbol{A})}-u_{1(\boldsymbol{B})}, \max \left\{u_{2(\boldsymbol{B})}-u_{2(\boldsymbol{A})}, 0\right\}\right\}, z_{1}^{\boldsymbol{A}}\right), \\
& \left(y_{2}^{\boldsymbol{A}}+\min \left\{u_{1(\boldsymbol{A})}-u_{1(\boldsymbol{B})}, \max \left\{u_{2(\boldsymbol{B})}-u_{2(\boldsymbol{A})}, 0\right\}\right\}, z_{2}^{\boldsymbol{A}}\right), \\
& \left.\left(y_{3}^{\boldsymbol{A}}, z_{3}^{\boldsymbol{A}}\right), \ldots,\left(y_{n}^{\boldsymbol{A}}, z_{n}^{\boldsymbol{A}}\right)\right], \\
\boldsymbol{A}_{3}= & \left(y_{1}^{\boldsymbol{A}_{2}}-\min \left\{u_{1\left(\boldsymbol{A}_{2}\right)}-u_{1(\boldsymbol{B})}, \max \left\{u_{3(\boldsymbol{B})}-u_{3(\boldsymbol{A})}, 0\right\}\right\}, z_{1}^{\boldsymbol{A}}\right), \\
& \left(y_{2}^{\boldsymbol{A}_{2}}, z_{2}^{\boldsymbol{A}}\right),\left(y_{3}^{\boldsymbol{A}}+\min \left\{u_{1\left(\boldsymbol{A}_{2}\right)}-u_{1(\boldsymbol{B})}, \max \left\{u_{3(\boldsymbol{B})}-u_{3(\boldsymbol{A})}, 0\right\}\right\}, z_{3}^{\boldsymbol{A}}\right), \\
& \left.\left(y_{4}^{\boldsymbol{A}}, z_{4}^{\boldsymbol{A}}\right), \ldots,\left(y_{n}^{\boldsymbol{A}}, z_{n}^{\boldsymbol{A}}\right)\right], \\
\vdots & \\
\boldsymbol{A}_{n}= & \left(y_{1}^{\boldsymbol{A}_{(n-1)}}-\min \left\{u_{1\left(\boldsymbol{A}_{(n-1)}\right)}-u_{1(\boldsymbol{B})}, \max \left\{u_{n(\boldsymbol{B})}-u_{n(\boldsymbol{A})}, 0\right\}\right\}, z_{1}^{\boldsymbol{A}}\right), \\
& \left(y_{2}^{\boldsymbol{A}_{2}}, z_{2}^{\boldsymbol{A}}\right), \ldots,\left(y_{(n-1)}^{\boldsymbol{A}_{(n-1)}}, z_{(n-1)}^{\boldsymbol{A}}\right), \\
& \left.\left(y_{n}^{\boldsymbol{A}}+\min \left\{u_{1\left(\boldsymbol{A}_{(n-1)}\right)}-u_{1(\boldsymbol{B})}, \max \left\{u_{n(\boldsymbol{B})}-u_{n(\boldsymbol{A})}, 0\right\}\right\}, z_{n}^{\boldsymbol{A}}\right)\right] .
\end{aligned}
$$

For all $i=1, \ldots, n-1, \boldsymbol{A}_{i}=\boldsymbol{A}_{i+1}$ or $\boldsymbol{A}_{i} \preceq \boldsymbol{A}_{i+1}$ according to Generalized Pigou-Dalton. If $u_{1(\boldsymbol{A})}=u_{1(\boldsymbol{B})}$, then $\boldsymbol{A}_{n}=\boldsymbol{A}$. Otherwise, by transitivity and Generalized Pigou-Dalton, $\boldsymbol{A}_{n} \succ \boldsymbol{A}$.

(iii) By (ii) and the fact that $\sum_{i} u_{i(\boldsymbol{A})}=0$, it follows that $u_{1\left(\boldsymbol{A}_{n}\right)}=u_{1(\boldsymbol{B})}$. Moreover, by the fact that $\boldsymbol{A} \mathbf{L D}^{u} \boldsymbol{B}$, it follows that $u_{2\left(\boldsymbol{A}_{n}\right)} \geq u_{2(\boldsymbol{B})}$. If $u_{2(\boldsymbol{A})} \geq u_{2(\boldsymbol{B})}$, then individual 2 has not received anything in the sequence in (ii). Hence, it 
follows that he is at least as badly off as persons $3, \ldots, n$. Alternatively, if $u_{2(\boldsymbol{A})}<u_{2(\boldsymbol{B})}$, then it follows from the fact that $\boldsymbol{A} \mathbf{L D}^{u} \boldsymbol{B}$ that $u_{2\left(\boldsymbol{A}_{n}\right)}=u_{2(\boldsymbol{B})}$. In any case, we may repeat exactly the same kind of sequence as in (ii), where we take from person 2 if $u_{2\left(\boldsymbol{A}_{n}\right)}>u_{2(\boldsymbol{B})}$ (otherwise nothing will happen in the sequence) and give to persons $3, \ldots, n$. As a consequence, we will establish $\boldsymbol{A}_{n}^{2}$, where $u_{2\left(\boldsymbol{A}_{n}^{2}\right)}=u_{2(\boldsymbol{B})}$ and $\boldsymbol{A}_{n}^{2}=\boldsymbol{A}_{n}$ or $\boldsymbol{A}_{n}^{2} \succ \boldsymbol{A}_{n}$. Similarly, we can do this for persons $3, \ldots, n$. In sum, we will establish $\boldsymbol{A}_{n}^{n}$, where $u_{i\left(\boldsymbol{A}_{n}^{n}\right)}=u_{i(\boldsymbol{B})}$ for all $i$ and where, by transitivity and Generalized Pigou-Dalton, $\boldsymbol{A}_{n}^{n} \succ \boldsymbol{A}$.

(iv) By (iii) and Unfairism, it follows that $\boldsymbol{A} \prec \boldsymbol{A}_{n}^{n} \sim \boldsymbol{B}$. Hence, by transitivity and (i), we have that $\widehat{\boldsymbol{A}} \prec \widehat{\boldsymbol{B}}$.

\section{Appendix B Unfairness Lorenz curves for differ- ent responsibility cuts (Not for pub- lication)}

Figure 9 shows the additional unfairness Lorenz curves referred to in footnote 10.

[Figure 9 about here.] 

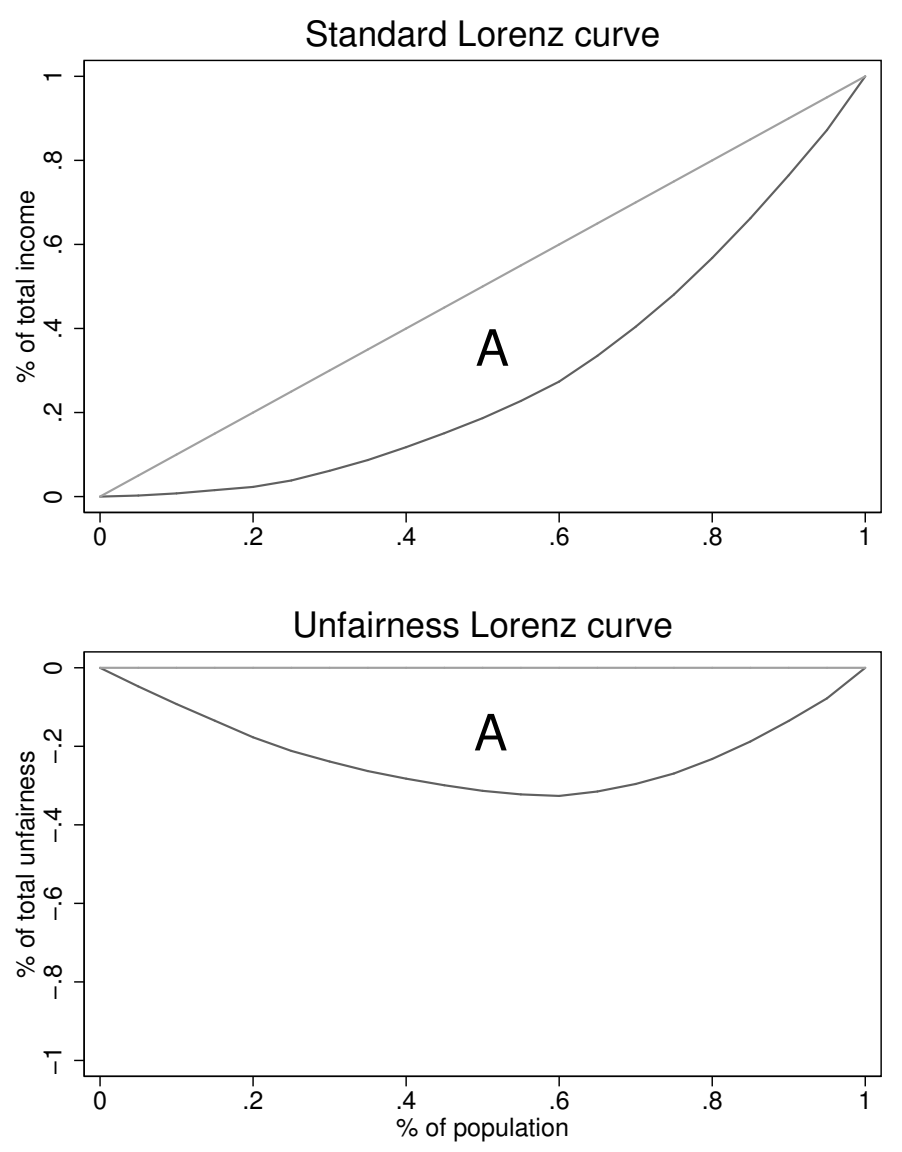

Figure 1: Graphical representations of standard and unfairness Lorenz curves. The figure displays the standard Lorenz curve and the corresponding unfairness Lorenz curve. The area between the standard Lorenz curve and the diagonal of the upper diagram is identical to the area between the unfairness Lorenz curve and the horizontal axis in the lower diagram (both labeled $A$ ). 


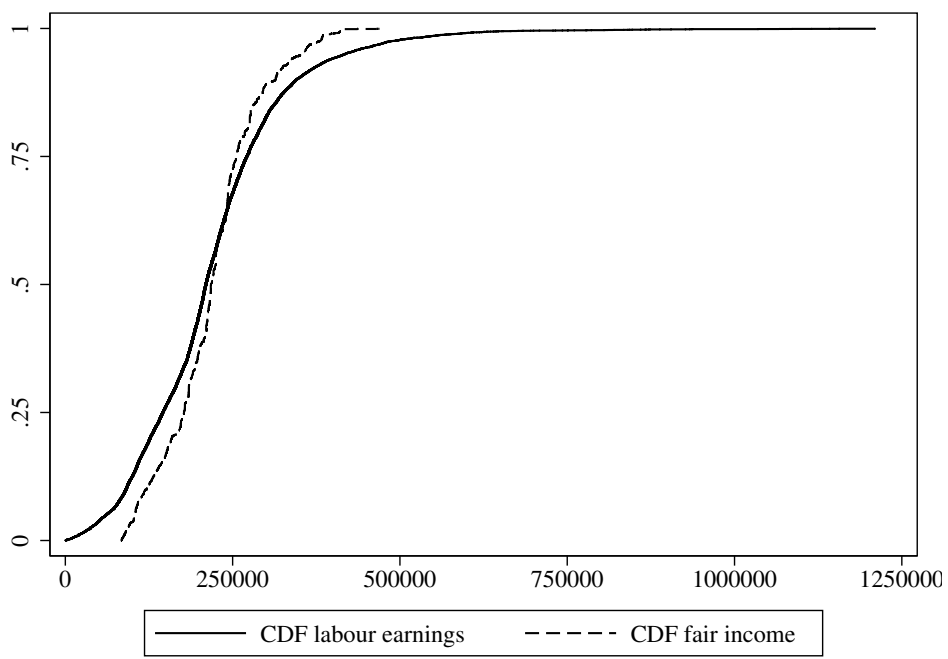

2005

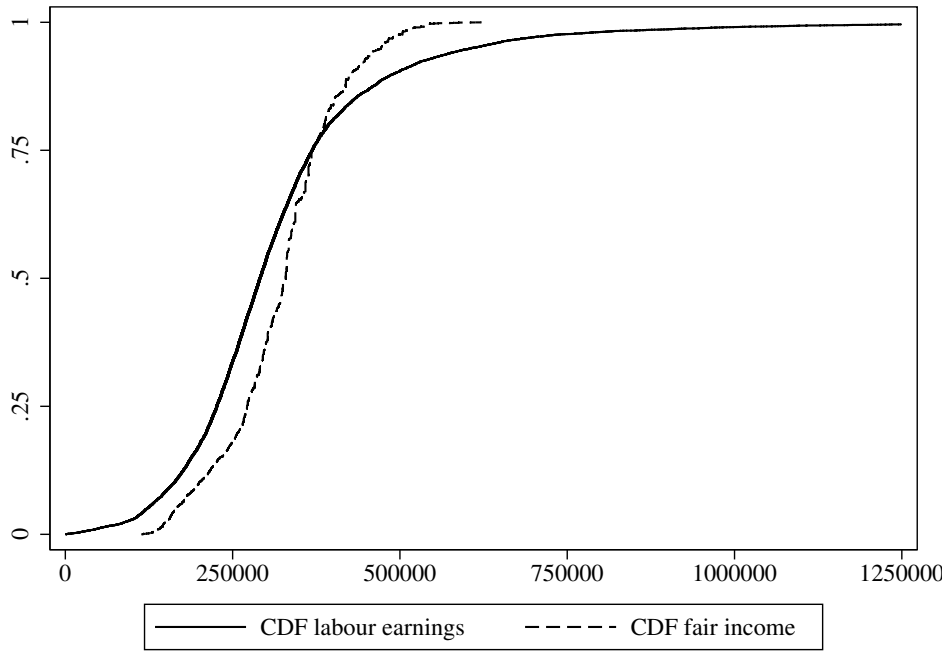

Figure 2: The distribution of labor earnings and fair income in 1986 and 2005. The figure displays the cumulative distribution functions (CDF) for labor earnings and fair income. The estimates of fair income are based on the responsibility set containing hours worked, years of education, sector (public versus private), and county of residence. 

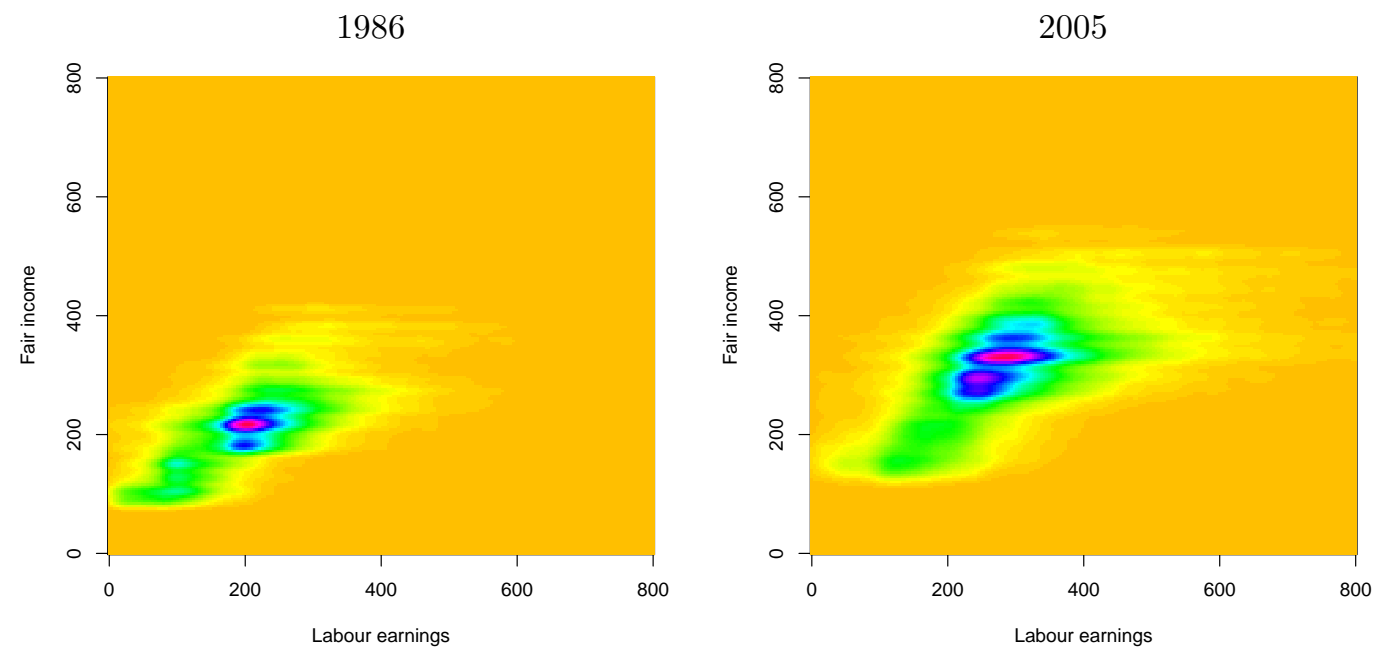

Figure 3: The joint distribution of labor earnings and fair income in $\mathbf{1 9 8 6}$ and 2005. The figures comprise a map that relates an individual's labor earnings to their fair income. The estimates of fair income are based on the responsibility set containing hours worked, years of education, sector (public versus private), and county of residence.

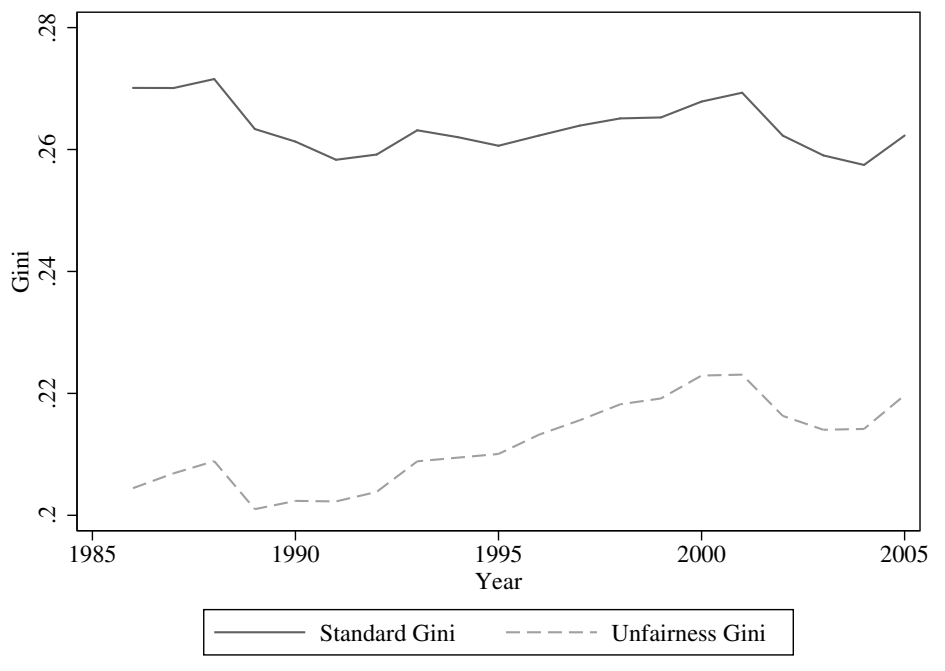

Figure 4: Unfairness and inequality over time. The figure shows the development of the standard Gini and the unfairness Gini in the period 1986 - 2005. The estimates of fair income are based on the responsibility set containing hours worked, years of education, sector (public versus private), and county of residence. 


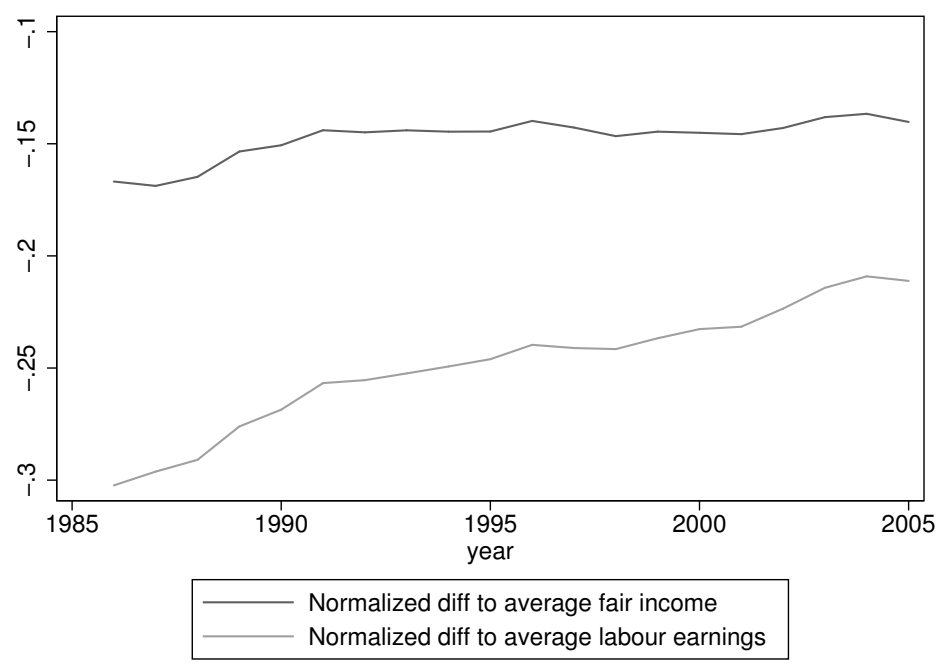

Figure 5: The development of labor earnings and fair incomes for females. The graph shows the normalized difference to average fair income, $\left(\bar{y}^{f}-\bar{z}^{f}\right) / \bar{y}$, and the normalized difference to average labor earnings, $\left(\bar{y}^{f}-\bar{y}\right) / \bar{y}$, where the bars denote yearly averages and the superscript " $f$ " denotes that the average is calculated for females only. The estimates of fair income are based on the responsibility set containing hours worked, years of education, sector (public versus private), and county of residence.

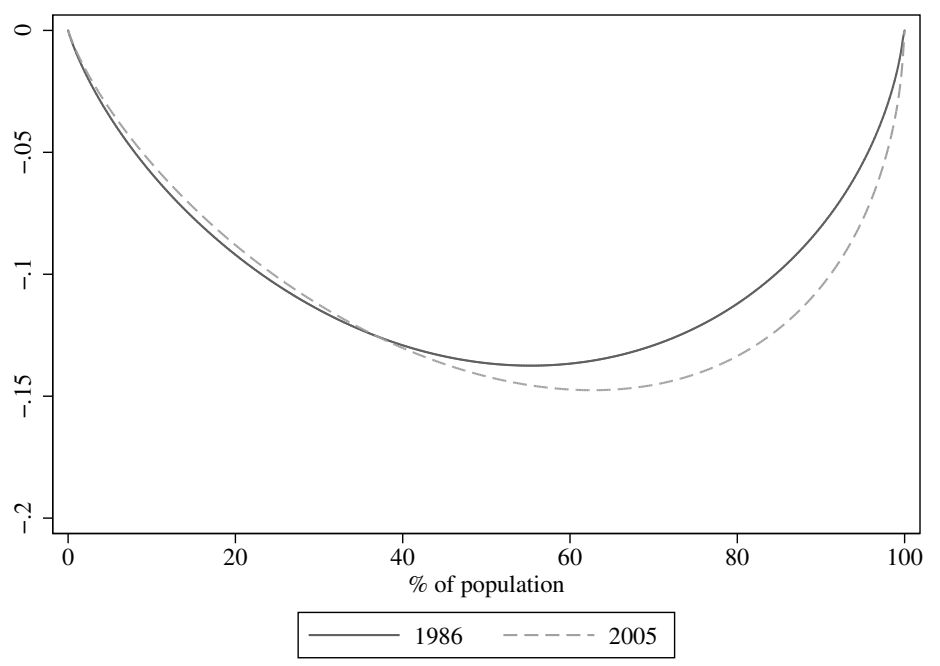

Figure 6: Unfairness Lorenz curves for 1986 and 2005. The estimates of fair income are based on the responsibility set containing hours worked, years of education, sector (public versus private), and county of residence. 


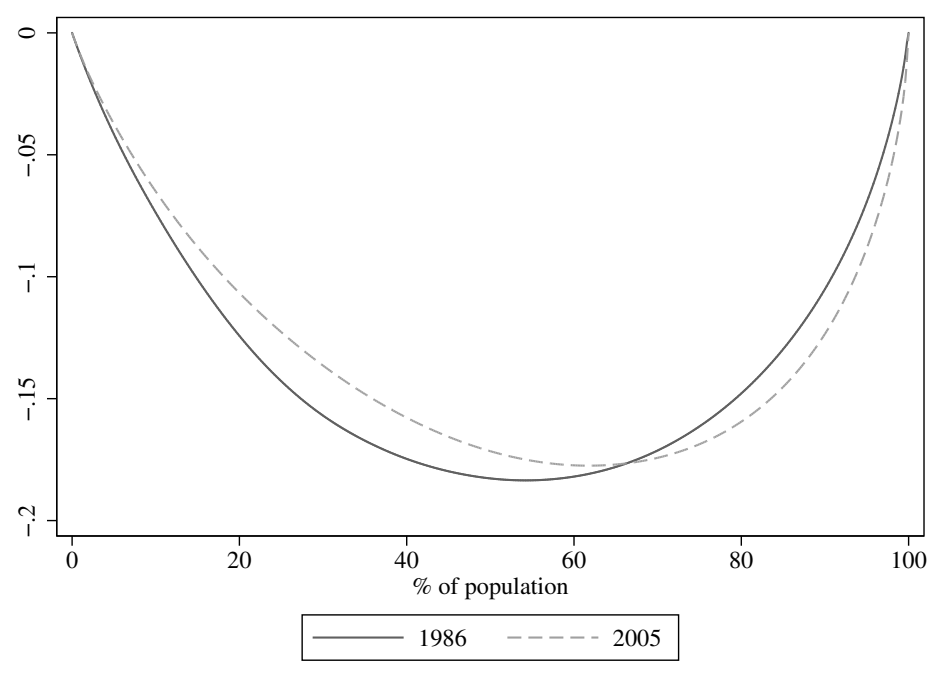

Figure 7: Standard Lorenz curves for 1986 and 2005. Standard Lorenz curves imply that the responsibility set is empty.

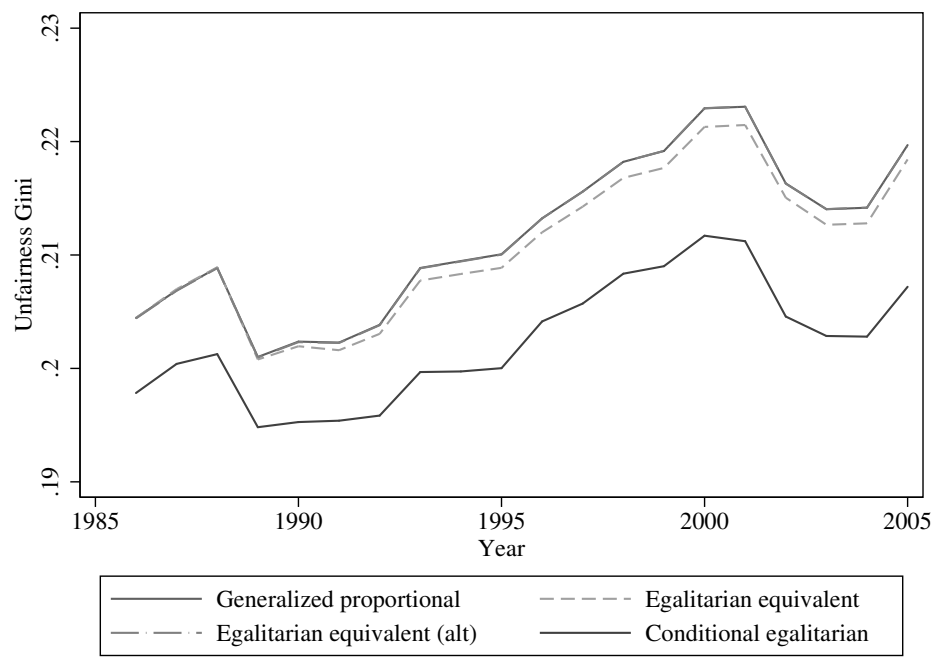

Figure 8: Unfairness Gini for different fairness principles. The figure shows the unfairness Gini for four different fairness principles: the generalized proportional principle, the two versions of the egalitarian equivalent principle, and the conditional egalitarian principle. The two formulations of the egalitarian equivalent principle cannot be distinguished in the figure. 
$\{\mathrm{H}\}$

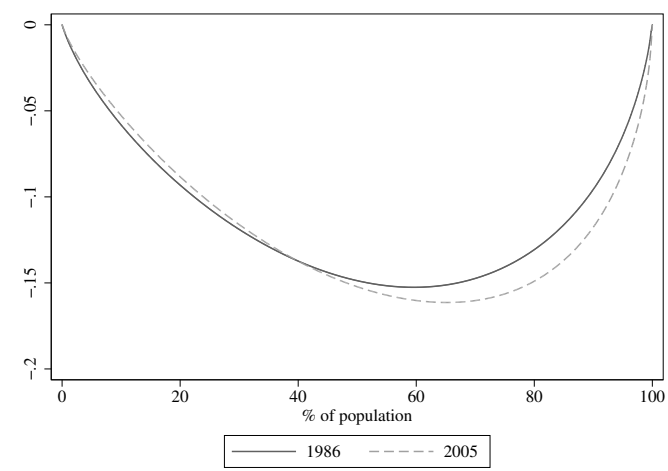

$\{\mathrm{H}, \mathrm{E}, \mathrm{P}\}$

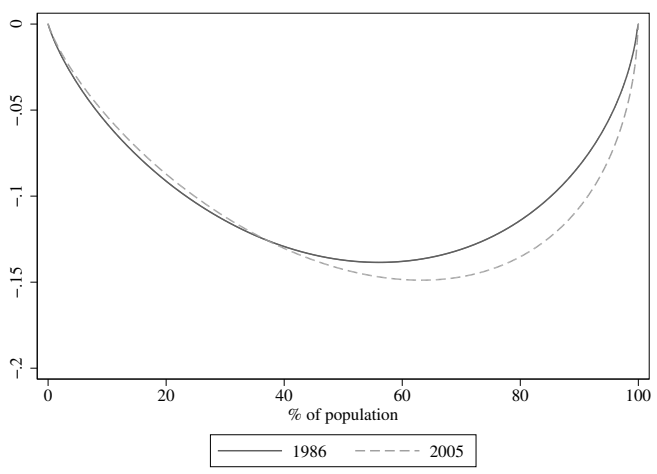

$\{\mathrm{H}, \mathrm{E}, \mathrm{P}, \mathrm{D}, \mathrm{F}\}$

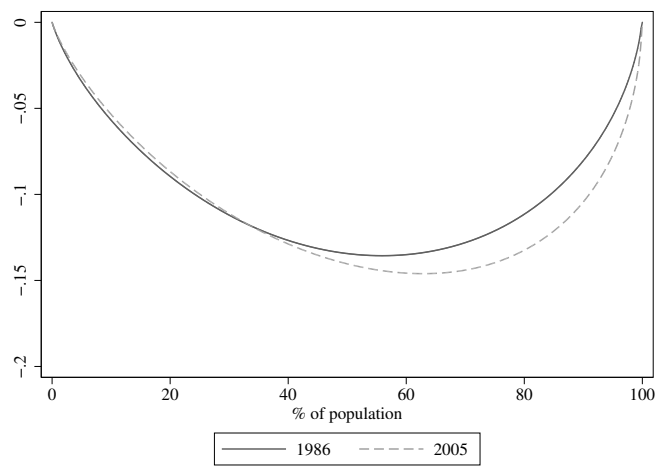

$\{\mathrm{H}, \mathrm{E}\}$

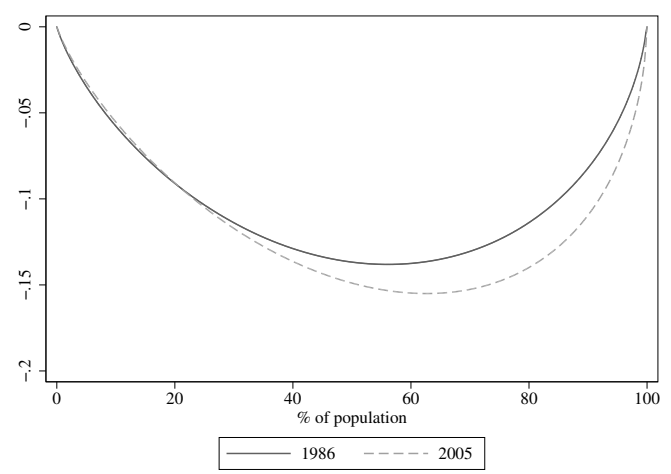

$\{\mathrm{H}, \mathrm{E}, \mathrm{P}, \mathrm{D}\}$

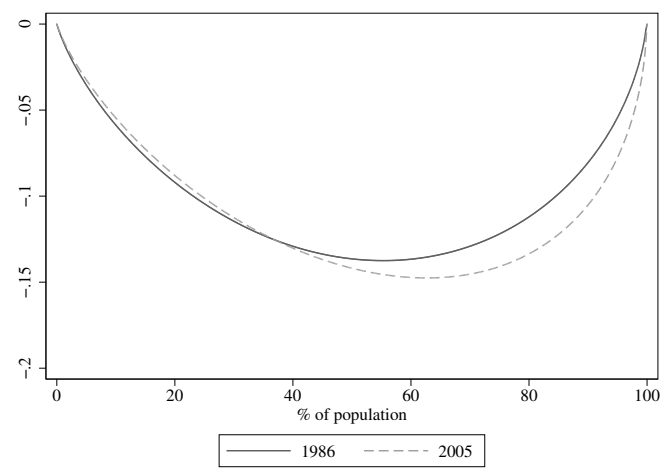

$\{\mathrm{H}, \mathrm{E}, \mathrm{P}, \mathrm{D}, \mathrm{F}, \mathrm{A}\}$

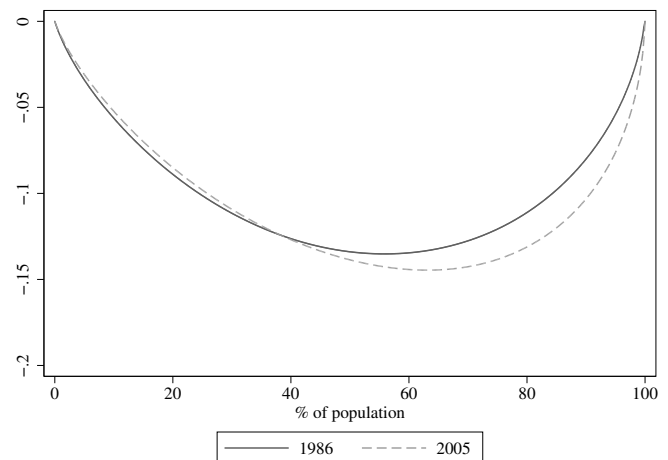

$\{\emptyset\}$ (Standard Lorenz)

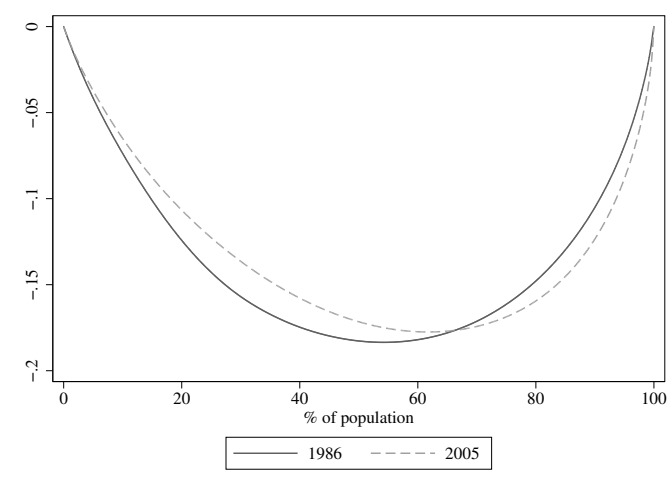

Figure 9: Unfairness Lorenz curves for 1986 and 2005. The figure shows the unfairness Lorenz curves for different responsibility sets. We consider the possibility of including hours worked $(\mathrm{H})$, years of education $(\mathrm{E})$, working in the public sector $(\mathrm{P})$, county of residence $(\mathrm{D})$, field of education $(\mathrm{F})$ and age $(\mathrm{A})$ in the responsibility set. The responsibility set given above each subfigure indicates which variables are part of $\boldsymbol{x}^{R}$, with the remaining being part of $\boldsymbol{x}^{N R}$. 


\begin{tabular}{|c|c|c|c|c|}
\hline & \multicolumn{2}{|c|}{1986} & \multicolumn{2}{|c|}{2005} \\
\hline Proportion female & \multicolumn{2}{|c|}{0.462} & \multicolumn{2}{|c|}{0.485} \\
\hline Proportion in public sector & \multicolumn{2}{|c|}{0.363} & \multicolumn{2}{|c|}{0.392} \\
\hline Proportion aged 30-39 & \multicolumn{2}{|c|}{0.419} & \multicolumn{2}{|c|}{0.350} \\
\hline Proportion aged $40-49$ & \multicolumn{2}{|c|}{0.342} & \multicolumn{2}{|c|}{0.342} \\
\hline Proportion aged 50-59 & \multicolumn{2}{|c|}{0.239} & \multicolumn{2}{|c|}{0.307} \\
\hline Proportion working less than 20 hours/week & \multicolumn{2}{|c|}{0.123} & \multicolumn{2}{|c|}{0.104} \\
\hline Proportion working 20-29 hours/week & \multicolumn{2}{|c|}{0.136} & \multicolumn{2}{|c|}{0.097} \\
\hline \multirow[t]{3}{*}{ Proportion working more than 30 hours/week } & \multicolumn{2}{|c|}{0.741} & \multicolumn{2}{|c|}{0.800} \\
\hline & \multicolumn{2}{|c|}{1986} & \multicolumn{2}{|c|}{2005} \\
\hline & mean & $\mathrm{SD}$ & mean & $\mathrm{SD}$ \\
\hline Years of education & 10.87 & 2.83 & 12.46 & 2.68 \\
\hline Labor earnings in thousand of 1998 NOK & 219 & 118 & 321 & 243 \\
\hline Number of observations & 994 & 96 & 1,335 & 078 \\
\hline
\end{tabular}

Note: Conversion to 1998 prices is made using the Consumer Price Index.

Table 2: Composition by gender: years of education, proportion in public sector, and hours worked

\begin{tabular}{lcccccc}
\hline & \multicolumn{2}{c}{ Male } & & \multicolumn{2}{c}{ Female } \\
\cline { 2 - 3 } \cline { 6 - 7 } & & 1986 & 2005 & & 1986 & 2005 \\
\hline Mean years of education & 11.21 & 12.47 & & 10.48 & 12.45 \\
Proportion in public sector & 0.238 & 0.224 & & 0.508 & 0.570 \\
Proportion working less than 20 hours/week & & 0.016 & 0.042 & & 0.249 & 0.169 \\
Proportion working 20-29 hours/week & & 0.026 & 0.022 & & 0.264 & 0.176 \\
Proportion working more than 30 hours/week & 0.959 & 0.936 & & 0.488 & 0.655 \\
\hline
\end{tabular}


Table 3: Labor earnings equations.

\begin{tabular}{|c|c|c|}
\hline & 1986 & 2005 \\
\hline \multirow[t]{2}{*}{ Hours worked: $20-29$} & 0.374 & 0.312 \\
\hline & $(0.00185)$ & $(0.00163)$ \\
\hline \multirow[t]{2}{*}{ Hours worked: >30 } & 0.728 & 0.622 \\
\hline & $(0.00162)$ & $(0.00126)$ \\
\hline \multirow[t]{2}{*}{ Years of education } & 0.0654 & 0.0653 \\
\hline & $(0.000249)$ & $(0.000172)$ \\
\hline \multirow[t]{2}{*}{ Employed in public sector } & 0.00894 & -0.108 \\
\hline & $(0.00112)$ & $(0.000908)$ \\
\hline \multirow[t]{2}{*}{ Age: $40-49$} & 0.100 & 0.122 \\
\hline & $(0.00108)$ & $(0.000879)$ \\
\hline \multirow[t]{2}{*}{ Age: $50-59$} & 0.0517 & 0.131 \\
\hline & $(0.00122)$ & $(0.000921)$ \\
\hline \multirow{2}{*}{ Female } & -0.392 & -0.252 \\
\hline & $(0.00122)$ & $(0.000899)$ \\
\hline \multirow[t]{2}{*}{ Humanities and Arts $^{\dagger}$} & -0.172 & -0.124 \\
\hline & $(0.00286)$ & $(0.00195)$ \\
\hline \multirow[t]{2}{*}{ Teacher training and Pedagogy ${ }^{\dagger}$} & -0.139 & -0.103 \\
\hline & $(0.00259)$ & $(0.00187)$ \\
\hline \multirow[t]{2}{*}{ Social Sciences and $\mathrm{Law}^{\dagger}$} & -0.108 & -0.0747 \\
\hline & $(0.00446)$ & $(0.00251)$ \\
\hline \multirow[t]{2}{*}{ Business and Administration $^{\dagger}$} & -0.00984 & 0.0284 \\
\hline & $(0.00157)$ & $(0.00129)$ \\
\hline \multirow[t]{2}{*}{ Natural sciences, Vocational, and Technical ${ }^{\dagger}$} & -0.0523 & -0.0158 \\
\hline & $(0.00161)$ & $(0.00120)$ \\
\hline \multirow[t]{2}{*}{ Health, Welfare, Sport ${ }^{\dagger}$} & 0.0201 & 0.0411 \\
\hline & $(0.00196)$ & $(0.00143)$ \\
\hline \multirow[t]{2}{*}{ Primary Industries ${ }^{\dagger}$} & -0.158 & -0.121 \\
\hline & $(0.00402)$ & $(0.00296)$ \\
\hline \multirow[t]{2}{*}{ Transport, Security, Other services ${ }^{\dagger}$} & 0.00489 & 0.0152 \\
\hline & $(0.00259)$ & $(0.00200)$ \\
\hline \multirow[t]{2}{*}{ Unspecified $^{\dagger}$} & -0.223 & -0.229 \\
\hline & $(0.0109)$ & $(0.00518)$ \\
\hline \multirow[t]{2}{*}{ Constant } & 11.36 & 11.62 \\
\hline & $(0.00402)$ & $(0.0334)$ \\
\hline Observations & 994296 & 1335078 \\
\hline$R^{2}$ & 0.481 & 0.401 \\
\hline
\end{tabular}

Note: The table shows the coefficients estimated for the labor earnings equation given in equation (6). The dependent variable is individual labor earnings. Hours worked are dummy coefficients for hours worked, and the omitted category is working less than 20 hours. Individuals are only included if they are between 30 and 60 years of age. They are divided into three age categories, with less than 40 years old being the omitted category. Type of education is classified according to the person's final degree, where the different categories are marked ${ }^{\dagger}$. The omitted category is "General subjects", which indicates that the person's final degree has no specialized or tertiary-level degree. Persons with no registered classification, such as many immigrants, are indicated as "Unspecified". Nineteen county dummies are also included in the regression mode, but not reported in this table. Standard errors are reported in parenthesis. 
Table 4: Decomposition of the change in inequality

\begin{tabular}{ccccc}
\hline & \multicolumn{2}{c}{ Elements from } & Unfairness Gini & Standard Gini \\
\cline { 2 - 3 } & 1986 & 2005 & & \\
\hline$(1)$ & $\boldsymbol{x}^{R}, \boldsymbol{x}^{N R}, \boldsymbol{\beta}, \boldsymbol{\gamma}, \varepsilon$ & - & 0.204 & 0.270 \\
$(2)$ & $\boldsymbol{x}^{R}, \boldsymbol{x}^{N R}, \boldsymbol{\gamma}, \varepsilon$ & $\boldsymbol{\beta}$ & 0.192 & 0.255 \\
$(3)$ & $\boldsymbol{x}^{R}, \boldsymbol{x}^{N R}, \boldsymbol{\beta}, \varepsilon$ & $\boldsymbol{\gamma}$ & 0.205 & 0.269 \\
$(4)$ & $\boldsymbol{x}^{N R}, \boldsymbol{\beta}, \boldsymbol{\gamma}, \varepsilon$ & $\overline{\boldsymbol{x}}^{R}$ & 0.204 & 0.261 \\
$(5)$ & $\boldsymbol{x}^{R}, \boldsymbol{\beta}, \boldsymbol{\gamma}, \varepsilon$ & $\overline{\boldsymbol{x}}^{N R}$ & 0.209 & 0.269 \\
$(6)$ & $\boldsymbol{x}^{R}, \boldsymbol{x}^{N R}, \boldsymbol{\beta}, \boldsymbol{\gamma}$ & $\bar{\varepsilon}$ & 0.208 & 0.272 \\
$(7)$ & - & $\boldsymbol{x}^{N R}, \boldsymbol{x}^{R}, \boldsymbol{\varepsilon}, \boldsymbol{\beta}, \boldsymbol{\gamma}$ & 0.220 & 0.262 \\
\hline
\end{tabular}

Note: The table reports calculations of unfairness and standard Gini using counterfactual incomes generated by replacing an element from the 1986-distribution with an element from the 2005-distribution. $\overline{\boldsymbol{x}}^{R}, \overline{\boldsymbol{x}}^{N R}$, and $\bar{\varepsilon}$ are constructed counterfactuals based on the distribution in 2005. The estimates of fair income are based on the responsibility set containing hours worked, years of education, sector (public versus private), and county of residence.

Table 5: Disaggregated decomposition of the change in inequality

\begin{tabular}{ccccc}
\hline & \multicolumn{2}{c}{ Elements from } & Unfairness Gini & Standard Gini \\
\cline { 2 - 3 }$(1)$ & $\boldsymbol{x}^{R}, \boldsymbol{x}^{N R}, \boldsymbol{\beta}, \boldsymbol{\gamma}, \varepsilon$ & - & & \\
\hline$(2)$ & $\boldsymbol{x}_{-H}^{R}, \boldsymbol{x}^{N R}, \boldsymbol{\beta}, \boldsymbol{\gamma}, \boldsymbol{\varepsilon}$ & $\overline{\boldsymbol{x}}_{H}^{R}$ & 0.204 & 0.270 \\
$(3)$ & $\boldsymbol{x}_{-E}^{R}, \boldsymbol{x}^{N R}, \boldsymbol{\beta}, \boldsymbol{\gamma}, \varepsilon$ & $\overline{\boldsymbol{x}}_{E}^{R}$ & 0.208 & 0.268 \\
$(4)$ & $\boldsymbol{x}_{-P}^{R}, \boldsymbol{x}^{N R}, \boldsymbol{\beta}, \boldsymbol{\gamma}, \varepsilon$ & $\overline{\boldsymbol{x}}_{P}^{R}$ & 0.203 & 0.277 \\
$(5)$ & $\boldsymbol{x}_{-D}^{R}, \boldsymbol{x}^{N R}, \boldsymbol{\beta}, \boldsymbol{\gamma}, \varepsilon$ & $\overline{\boldsymbol{x}}_{D}^{R}$ & 0.204 & 0.270 \\
$(6)$ & $\boldsymbol{x}^{N R}, \boldsymbol{\beta}, \boldsymbol{\gamma}, \varepsilon$ & $\boldsymbol{x}^{R}$ & 0.204 & 0.273 \\
$(7)$ & $\boldsymbol{x}^{R}, \boldsymbol{x}_{-F}^{N R}, \boldsymbol{\beta}, \boldsymbol{\gamma}, \varepsilon$ & $\overline{\boldsymbol{x}}_{F}^{N R}$ & 0.205 & 0.261 \\
$(8)$ & $\boldsymbol{x}^{R}, \boldsymbol{x}_{-A}^{N R}, \boldsymbol{\beta}, \boldsymbol{\gamma}, \varepsilon$ & $\overline{\boldsymbol{x}}_{A}^{N R}$ & 0.207 & 0.277 \\
$(9)$ & $\boldsymbol{x}^{R}, \boldsymbol{x}_{-S}^{N R}, \boldsymbol{\beta}, \boldsymbol{\gamma}, \varepsilon$ & $\overline{\boldsymbol{x}}_{S}^{R}$ & 0.215 & 0.270 \\
$(10)$ & $\boldsymbol{x}^{R}, \boldsymbol{\beta}, \boldsymbol{\gamma}, \varepsilon$ & $\boldsymbol{x}^{N R}$ & 0.209 & 0.270 \\
$(11)$ & - & $\boldsymbol{x}^{N R}, \boldsymbol{x}^{R}, \boldsymbol{\beta}, \boldsymbol{\gamma}, \varepsilon$ & 0.220 & 0.269 \\
\hline
\end{tabular}

Note: The table reports calculations of unfairness and standard Gini using counterfactual incomes generated by replacing an element from the 1986-distribution with an element from the 2005-distribution. $\boldsymbol{x}_{-k}^{R}$ is the vector of responsibility factors, excluding factor $k$; similarly for $\boldsymbol{x}_{-k}^{N R}$. $\overline{\boldsymbol{x}}_{k}^{R}$ is the constructed counterfactual for responsibility factor $k$; similarly for $\overline{\boldsymbol{x}}_{k}^{N R}$. The estimates of fair income are based on the responsibility set containing hours worked $(\mathrm{H})$, years of education $(\mathrm{E})$, public or private sector $(\mathrm{P})$, and county of residence $(\mathrm{D})$, and the non-responsibility factors field of eduction $(\mathrm{F})$, age $(\mathrm{A})$, and sex $(\mathrm{S})$. 
Table 6: Unfairness Gini for different responsibility cuts.

\begin{tabular}{lrr}
\hline & \multicolumn{2}{c}{$\mathbf{G}^{u}$} \\
\cline { 2 - 3 } Responsibility set & 1986 & 2005 \\
\hline$\emptyset$ (standard Gini) & 0.270 & 0.262 \\
$\{H\}$ & 0.223 & 0.235 \\
$\{H, E\}$ & 0.206 & 0.229 \\
$\{H, E, P\}$ & 0.206 & 0.221 \\
$\{H, E, P, D\}$ & $\mathbf{0 . 2 0 4}$ & $\mathbf{0 . 2 2 0}$ \\
$\{H, E, P, D, F\}$ & 0.201 & 0.217 \\
$\{H, E, P, D, F, A\}$ & 0.200 & 0.214 \\
$\{H, E, P, D, F, A, \varepsilon\}$ & 0.120 & 0.076 \\
\hline
\end{tabular}

Note: We consider the possibility of including hours worked $(\mathrm{H})$, years of education $(\mathrm{E})$, working in the public sector $(\mathrm{P})$, county of residence $(\mathrm{D})$, field of education $(\mathrm{F})$, age $(\mathrm{A})$ and the unobservable factors $(\varepsilon)$ in the responsibility set. The responsibility set indicates which variables are considered to be part of $\boldsymbol{x}^{R}$, with the remaining being part of $\boldsymbol{x}^{N R}$. 
Table 7: Unfairness Gini corrected for family background and innate ability

\begin{tabular}{lccccc}
\hline \multirow{2}{*}{ A. Family background } & & & \\
& \multicolumn{2}{c}{ baseline } & & \multicolumn{2}{l}{ with corrections } \\
\cline { 2 - 3 } \cline { 5 - 6 } Responsibility set & 1986 & 2005 & & 1986 & 2005 \\
\hline$\emptyset$ (standard Gini) & 0.260 & 0.260 & & 0.260 & 0.260 \\
$\{H\}$ & 0.218 & 0.233 & & 0.218 & 0.233 \\
$\{H, E\}$ & 0.217 & 0.233 & & 0.208 & 0.229 \\
$\{H, E, P\}$ & 0.218 & 0.231 & & 0.207 & 0.221 \\
$\{H, E, P, D\}$ & 0.215 & 0.229 & & 0.205 & 0.219 \\
$\{H, E, P, D, F\}$ & 0.215 & 0.231 & & 0.201 & 0.218 \\
$\{H, E, P, D, F, A\}$ & 0.215 & 0.230 & & 0.200 & 0.217 \\
\hline
\end{tabular}

B. Innate ability (IQ score) and family background

\begin{tabular}{llllll} 
& \multicolumn{2}{c}{ baseline } & & with corrections \\
\cline { 2 - 3 } \cline { 5 - 6 } Responsibility set & 1986 & 2005 & & 1986 & 2005 \\
\hline$\emptyset$ (standard Gini) & 0.181 & 0.241 & & 0.181 & 0.241 \\
$\{H\}$ & 0.179 & 0.236 & & 0.179 & 0.236 \\
$\{H, E\}$ & 0.179 & 0.236 & & 0.177 & 0.235 \\
$\{H, E, P\}$ & 0.180 & 0.237 & & 0.176 & 0.232 \\
$\{H, E, P, D\}$ & 0.173 & 0.233 & & 0.171 & 0.229 \\
$\{H, E, P, D, F\}$ & 0.169 & 0.230 & & 0.170 & 0.228 \\
$\{H, E, P, D, F, A\}$ & 0.169 & 0.229 & & 0.170 & 0.225 \\
\hline
\end{tabular}

Note: The estimates with corrections are based on replacing years of education with a variable that captures the difference between the actual years of education and the predicted years of education. In panel A, the prediction is based on family background (years of education of mother and father, interaction of these, and dummies for the childhood county), in panel B it also controls for innate ability. Panel A reports results for the subsample for which we have family background variables; Panel B reports results for the subsample for which we have both family background variables and IQ-score. 
Table 8: The development of the unfairness Gini (post-tax)

\begin{tabular}{lrr}
\hline & \multicolumn{2}{c}{$\mathbf{G}^{u}$} \\
\cline { 2 - 3 } Responsibility set & 1986 & 2005 \\
\hline$\emptyset$ (standard Gini) & 0.205 & 0.219 \\
$\{H\}$ & 0.159 & 0.192 \\
$\{H, E\}$ & 0.158 & 0.192 \\
$\{H, E, P\}$ & 0.157 & 0.184 \\
$\{H, E, P, D\}$ & $\mathbf{0 . 1 5 8}$ & $\mathbf{0 . 1 8 4}$ \\
$\{H, E, P, D, F\}$ & 0.153 & 0.181 \\
$\{H, E, P, D, F, A\}$ & 0.152 & 0.178 \\
\hline
\end{tabular}

Note: The ufairness Gini is reported for imputed post-tax incomes. We consider the possibility of including hours worked $(\mathrm{H})$, years of education $(\mathrm{E})$, working in the public sector $(\mathrm{P})$, county of residence (D), field of education (F) and age (A) in the responsibility set. The responsibility set indicates which variables are considered to be part of $\boldsymbol{x}^{R}$, with the remaining being part of $\boldsymbol{x}^{N R}$. 